\title{
Protective role of cortistatin in pulmonary inflammation and fibrosis
}

\author{
Margarita Barriga $^{1}$ | Raquel Benitez ${ }^{1}$ | Viviane Ferraz-de-Paula ${ }^{1,2}$ | \\ Marina Garcia-Frutos $^{1}$ | Marta Caro ${ }^{1}$ | Gema Robledo $^{1}$ | Francisco O'Valle ${ }^{3}$ \\ Jenny Campos-Salinas ${ }^{1}$ | Mario Delgado ${ }^{1}$
}

\author{
${ }^{1}$ Department of Immunology and Cell Biology, \\ Institute of Parasitology and Biomedicine \\ Lopez-Neyra IPBLN-CSIC, Granada, Spain \\ ${ }^{2}$ Department of Clinical and Toxicological \\ Analysis, School of Pharmaceutical Sciences, \\ University of São Paulo, São Paulo, Brazil \\ ${ }^{3}$ Pathology Department, School of Medicine, \\ IBIMER, CIBM, University of Granada and \\ Biosanitary Research Institute IBS-Granada, \\ Granada, Spain

\section{Correspondence} \\ Mario Delgado, Department of Immunology \\ and Cell Biology, Institute of Parasitology and \\ Biomedicine Lopez-Neyra IPBLN-CSIC, PT \\ Salud, Granada, Spain. \\ Email: mdelgado@ipb.csic.es \\ Funding information \\ Fundação de Amparo à Pesquisa do Estado de \\ São Paulo, Grant/Award Number: \\ 12/21767-5; Ministerio de Ciencia e \\ Innovación, Grant/Award Number: \\ SAF2015-67787-R
}

Background and Purpose: Acute lung injury (ALI), acute respiratory distress syndrome (ARDS) and pulmonary fibrosis remain major causes of morbidity, mortality and a healthcare burden in critically ill patient. There is an urgent need to identify factors causing susceptibility and for the design of new therapeutic agents. Here, we evaluate the effectiveness of the immunomodulatory neuropeptide cortistatin to regulate pulmonary inflammation and fibrosis in vivo.

Experimental Approach: ALI/ARDS and pulmonary fibrosis were induced experimentally in wild-type and cortistatin-deficient mice by pulmonary infusion of the bacterial endotoxin LPS or the chemotherapeutic drug bleomycin, and the histopathological signs, pulmonary leukocyte infiltration and cytokines, and fibrotic markers were evaluated.

Key Results: Partially deficient mice in cortistatin showed exacerbated pulmonary damage, pulmonary inflammation, alveolar oedema and fibrosis, and subsequent increased respiratory failure and mortality when challenged to LPS or bleomycin, even at low doses. Treatment with cortistatin reversed these aggravated phenotypes and protected from progression to severe ARDS and fibrosis, after high exposure to both injury agents. Moreover, cortistatin-deficient pulmonary macrophages and fibroblasts showed exaggerated ex vivo inflammatory and fibrotic responses, and treatment with cortistatin impaired their activation. Finally, the protective effects of cortistatin in $\mathrm{ALI}$ and pulmonary fibrosis were partially inhibited by specific antagonists for somatostatin and ghrelin receptors.

Conclusion and Implications: We identified cortistatin as an endogenous inhibitor of pulmonary inflammation and fibrosis. Deficiency in cortistatin could be a marker of poor prognosis in inflammatory/fibrotic pulmonary disorders. Cortistatin-based therapies could emerge as attractive candidates to treat severe ALI/ARDS, including SARS-CoV-2-associated ARDS.

Abbreviations: ALI, acute lung injury; ARDS, acute respiratory distress syndrome; BALF, bronchoalveolar lavage fluid; CST, cortistatin; Cort, cortistatin gene; CTGF, connective tissue growth factor; [D-Lys ${ }^{3}$ ]-GHRP-6, [D-Lys ${ }^{3}$ ]-growth hormone-releasing peptide 6; i.n., intranasally; IPF, idiopathic pulmonary fibrosis; CXCL2/MIP-2, macrophage inflammatory protein-2; SARS-CoV-2, severe acute respiratory syndrome coronavirus 2 ; SST, somatostatin receptor; $\alpha \mathrm{SMA}, \alpha$-smooth muscle actin. 


\section{KEYWORDS}

acute lung injury, fibroblasts, macrophages, neuropeptide, pulmonary inflammation

\section{INTRODUCTION}

Despite major treatment efforts made over the past decades, acute lung injury (ALI) and its most severe form, acute respiratory distress syndrome (ARDS), characterized by refractory hypoxia, severe inflammation, increased vascular permeability and diffuse alveolar damage, remains a major cause of morbidity and mortality in critically ill patients (Matthay et al., 2017). ARDS can occur as a result of different clinical conditions, such as infections, pulmonary contusion and inhalation injury, that directly damage the pulmonary epithelial and endothelial cells and compromise alveolar-capillary barrier. ARDS is caused and sustained by an uncontrolled inflammatory activation characterized by massive release of cytokines and chemokines, diffuse lung oedema, inflammatory cell infiltration and disseminated coagulation. In this sense, evidence indicates that the massive pulmonary infiltration (neutrophils and macrophages) and the subsequent inflammatory cytokine storm are closely related to secondary complications such as lung injury/ARDS, multiorgan failure and ultimately poor prognosis in the new severe acute respiratory syndrome coronavirus 2 (SARS-CoV-2) pandemic (Mehta et al., 2020; Zhou et al., 2020). Moreover, in patients who develop ARDS, the progression of ALI to pulmonary fibrosis portends a fatal outcome, with severe disruption of lung function and elevated mortality (George et al., 2020). As in other cases of pulmonary fibrosis which are caused by persistent infection, oxidative stress and inflammatory insults, the injury to alveolar epithelial cells activates pulmonary fibroblasts, promoting their transformation to extracellular matrix-producing myofibroblasts (Wynn, 2011). These findings highlight the urgent need to develop safe and effective therapeutic agents with capacity to limit both inflammatory and fibrotic responses in injured lung. Moreover, due to the heterogeneous progression and severity of disease in patients with ALI/ARDS, it is critical to identify factors and genes that predispose/protect from the development of the most severe forms of lung injury and progressive lung fibrosis.

Cortistatin-14 (CST-14) is a cyclic neuropeptide belonging to the somatostatin family that has emerged as a potent immunomodulatory agent (Gonzalez-Rey \& Delgado, 2008) with capacity to protect against exacerbated inflammatory and autoimmune responses in various experimental models of sepsis, rheumatoid arthritis, colitis, myocarditis and multiple sclerosis (Delgado-Maroto et al., 2017; Gonzalez-Rey, Chorny, Del Moral, et al., 2007; Gonzalez-Rey, Chorny, Robledo, \& Delgado, 2006; Gonzalez-Rey, Varela, Sheibanie, et al., 2006; Souza-Moreira et al., 2013). These effects are exerted through the regulation of a plethora of inflammatory cytokines and chemokines, and by deactivating macrophages and lymphocytes, indicating that it is a multitargeted and safe modulator of the cytokine storm in various tissues. However, the endogenous role of cortistatin in the modulation of immune response has been scarcely investigated,

\section{What is already known}

- Acute respiratory distress syndrome (ARDS) and idiopathic pulmonary fibrosis remain major causes of morbidity/mortality worldwide.

- Cortistatin is an immunomodulatory neuropeptide with potential to regulate inflammation and fibrosis in several tissues.

\section{What does this study add}

- Treatment with cortistatin ameliorates inflammation and fibrosis progression in two preclinical models of lung injury.

- Cortistatin acts as a potent endogenous inhibitor of pulmonary inflammation and fibrosis.

\section{What is the clinical significance}

- Cortistatin deficiency could be a marker for poor prognosis in inflammatory and fibrotic pulmonary disorders.

- Cortistatin-based therapies emerge as attractive candidates to treat severe forms of infection-induced ARDS, including SARS-CoV-2.

with some paradoxical effects found in cortistatin-deficient animals (Qiu et al., 2020; Souza-Moreira et al., 2013). Moreover, its role in ALI and fibrotic disorders is completely unknown, although some data point out to a potential antifibrotic action of this neuropeptide. Thus, cortistatin receptors (somatostatin (SST) $)_{5}$ receptors and ghrelin receptor GHSR) are expressed in fibroblasts, and other SST receptor agonists have been described that exert antifibrotic responses in various tissues, including lung (Borie et al., 2008; Egger et al., 2014; Tug et al., 2013). Therefore, cortistatin could converge immunomodulatory and antifibrotic properties that synergistically might contribute to ameliorate inflammatory and fibroproliferative disorders in the lung. In this study, we will evaluate the therapeutic potential of cortistatin in two well-established experimental models of ALI and pulmonary fibrosis, as well as the immune and antifibrotic mechanisms involved. We will also investigate the role of cortistatin as a potential endogenous protective factor in the progression to severe $\mathrm{ALI}$ and pulmonary fibrosis in mice that are partially or totally deficient in this neuropeptide. 


\section{2 | METHODS}

\subsection{Animals and ethic statement}

The experiments reported in this study followed the ethical guidelines for investigations of experimental animals approved by the Animal Care and Use Board and the Ethical Committee of Spanish Council of Scientific Research (Number 388/2015) and performed in accordance with the guidelines from Directive 2010/63/EU of the European Parliament on the protection of animals used for scientific purposes. Animal studies are reported in compliance with the ARRIVE guidelines (Percie du Sert et al., 2020) and with the recommendations made by the British Journal of Pharmacology (Lilley et al., 2020). Mice lacking the gene for cortistatin (Cort-/-) were a generous gift of Dr Luis de Lecea (Stanford University, La Jolla, CA, USA) and were generated in a C57BL/ 6 background and backcrossed with C57BL/ 6 mice for 10 generations as previously described (Cordoba-Chacon et al., 2011). Mice heterozygous (Cort+/-) for cortistatin were generated by crossing female Cort-/- and male Cort $+/+$ mice. Cort $+/$ - breeding pairs were used to generate a littermate colony of wild-type (Cort $+/+)$, heterozygous (Cort $+/-)$ and knockout (Cort-/-) mice for cortistatin. Both male and female mice (20- to 24-g body weight, 8-10 weeks old) were used in all experiments described in this study, and no differences were found between sexes. All animals were housed in a controlled-temperature/humidity environment $\left(22 \pm 1^{\circ} \mathrm{C}, \quad 60-70 \%\right.$ relative humidity) in individual cages (10 mice per cage, with wood shaving bedding and nesting material), with a 12-h light/dark cycle (lights on at 7:00 AM) and fed with rodent chow (Global Diet 2018, Harlan) and tap water ad libitum. Mice were allowed to acclimatize to the experimental room for $1 \mathrm{~h}$ before experiments. Mice were randomly assigned to the different experimental groups. Experiments were designed to make sample sizes relatively equal. However, this was not possible in some experiments due to the differential mortality rates occurring between genotypes and response to bleomycin. None of the animals were excluded from the study. Power calculations were performed using the software G*Power (www.gpower.hhu.de, RRID: SCR_013726) to ensure that adequate group sizes were used for the studies detailed below. For in vivo animal models, we calculated a minimum size of five to eight mice per group in order to have a power $>0.95$ of detecting approximately a $30 \%$ change, assuming an SD of $30 \%$ at a significance level of $P<0.05$, expecting an effect size of 1.82 for ANOVA tests. In primary cell cultures, for effect sizes between 3.1 and 4, experiments were repeated at least four times to obtain $P<0.05$ and a power $>0.95$.

\section{2 | Materials}

Unless otherwise indicated, all purchased reagents used in this study were from Sigma-Aldrich (St. Louis, MO, USA). Bleomycin sulphate (with specific activity of 1.6-2.0 U. $\mathrm{mg}^{-1}$, from Sigma-Aldrich, cat\#B8616) was dissolved in saline solution $(0.9 \% \mathrm{NaCl})$ at $1 \mathrm{mg} \cdot \mathrm{ml}^{-1}$ $\left(1.8 \mathrm{U} \cdot \mathrm{ml}^{-1}\right)$ and stored at $-20^{\circ} \mathrm{C}$ and was diluted in saline at the indicated doses immediately before its injection in animals. Mouse cortistatin-29 (from Bachem, Bubendorf, Switzerland, cat\#H-6444) was dissolved in $\mathrm{dd}_{2} \mathrm{O}$ and stored at $-80^{\circ} \mathrm{C}$ at a dose of $0.1 \mathrm{mM}$ and was diluted in $\mathrm{ddH}_{2} \mathrm{O}$ (used as vehicle) at the indicated dose and volume immediately before its use in the experimental models. LPS (from Escherichia coli serotype 055:B5, Sigma-Aldrich, cat\#L-2880) was dissolved in saline at $2 \mathrm{mg} \cdot \mathrm{ml}^{-1}$ and stored at $-20^{\circ} \mathrm{C}$ until its use. The antagonist for $\mathrm{SST}_{1-5}$ receptors, cyclosomatostatin (SigmaAldrich, cat\#C4801), and the antagonist for ghrelin receptor, [D-Lys ${ }^{3}$ ]growth hormone-releasing peptide 6 ([D-Lys $\left.{ }^{3}\right]-G H R P-6$, SigmaAldrich, cat\#G4535), were dissolved in $\mathrm{dd}_{2} \mathrm{O}$ at $0.1 \mathrm{mM}$ and stored at $-80^{\circ} \mathrm{C}$ until their use and diluted in saline solution at the indicated dose and volume immediately before their use in the experimental models. Doses of LPS, bleomycin, cortistatin, cyclosomatostatin and [D-Lys ${ }^{3}$ ]-GHRP-6 used in this study were chosen on the basis of our previous experience and that of other laboratories with these peptides and substances (Delgado-Maroto et al., 2017; Gonzalez-Rey, Chorny, Varela, et al., 2006; Gonzalez-Rey, Varela, Sheibanie, et al., 2006; Kolb et al., 2020; Morell et al., 2014; Tsushima et al., 2009).

\section{3 | Antibodies}

Antibodies used for flow cytometry were as follows:- anti-mouse CD16/CD32 (clone 2.4G2, BD Pharmingen, San Jose, CA, USA, cat \#553130, RRID:AB_394655), phycoerythrin (PE)-labelled anti-mouse CD45 monoclonal antibody (clone 16A, BD Pharmingen, cat\#553099, RRID:AB_394625), allophycocyanin (APC)-Cy7-labelled anti-mouse CD3 (clone 17A2, BD Pharmingen, cat\#560590, RRID: $A B$ 1727461), APC-labelled anti-mouse CD64 (clone X54-5/7.1, eBioscience/Thermo Fisher, cat\#17-0641-82, RRID:AB_2735010) or FITC-labelled anti-mouse Ly6G antibodies (clone RB6-8C5, BD Bioscience, cat\#553126, RRID:AB_394642). Capture and biotinylated antibodies used for sandwich ELISA were as follows:- for TNF- $\alpha$ detection (BD Pharmingen): capture antibody (clone G281-2626, cat\#551225, RRID:AB_394102) and biotin antibody (clone MP6-XT3, cat\#554415, RRID:AB_395378); for IL-6 detection (BD Pharmingen): capture antibody (clone MP5-20F3, cat\#554398, RRID:AB_2127480) and biotin antibody (clone MP5-32C11, cat\#554402, RRID: $A B$ _395368); for TGF- $\beta 1$ detection (BD Pharmingen): capture antibody (clone A75-2, cat\#555052, RRID:AB_395673) and biotin antibody (clone A75-3, cat\#555053, RRID:AB_395674); for macrophage inflammatory protein-2 (CXCL2/MIP-2) detection (PeproTech, London, UK): capture antibody (cat\#500-P130, RRID:AB_148106) and biotin antibody (cat\#500-P130Bt, RRID:AB_148107); and for IL-1 $\beta$ detection (PeproTech): capture antibody (cat\#500-P51, RRID: AB_147963) and biotin antibody (cat\#500-P51Bt, RRID:AB_147630). Antibodies used for immunofluorescence analysis of tissues were as follows: mouse anti-mouse $\alpha$-smooth muscle actin ( $\alpha \mathrm{SMA}$ ) antibody (clone 1A4, Sigma-Aldrich, cat\#A5228, RRID:AB_262054) and Alexa Fluor 568-conjugated goat anti-mouse antibody (Life Biotechnologies/Thermo Fisher, cat\#A11004, RRID:AB_2534072). Primary 
antibodies used for western blot analysis of pulmonary fibroblasts, all from Cell Signaling (Danvers, MA, USA), were as follows: rabbit anti-mouse phospho-Akt (cat\#2968, RRID:AB_1264114), mouse anti-mouse Akt (cat\#2920, RRID:AB_1147620), mouse anti-mouse phospho-p38 MAPK (cat\#9216, RRID:AB_331296), rabbit antimouse p38 MAPK (cat\#9212, RRID:AB_330713), mouse anti-mouse phospho-p42/p44 MAPK (ERK1/2, cat\#9106, RRID:AB_331768) and rabbit anti-mouse ERK1/2 (cat\#4695, RRID:AB_390779). Secondary antibodies used for western blot analysis of pulmonary fibroblasts, all from LI-COR Biosciences (Lincoln, NE, USA), were as follows: IRDye 800CW-conjugated goat anti-mouse (cat\#926-32210, RRID:AB_621842), IRDye 680RD-conjugated goat anti-rabbit (cat\#926-68071, RRID:AB_10956166), IRDye 680RD-conjugated goat anti-mouse (cat\#926-68070, RRID:AB_10956588) and IRDye $800 \mathrm{CW}$-conjugated goat anti-rabbit (cat\#926-32211, RRID: $\left.A B \_621843\right)$. Antibodies for immunofluorescence analysis of pulmonary fibroblasts were as follows: rabbit anti-mouse Smad2/3 antibody (Cell Signaling, cat\#5678, RRID:AB_10693547) and Alexa Fluor 488-conjugated donkey anti-rabbit antibody (Thermo Fisher, ca\#A21206, RRID:AB_2535792).

\section{$2.4 \quad$ Induction of acute lung injury (ALI)}

To investigate the effect of cortistatin deficiency in the severity of ALI, Cort+/+, Cort+/- and Cort-/- mice were infused intranasally (i.n.) with the bacterial endotoxin LPS (1-mg. $\mathrm{kg}^{-1}$ mouse, in $20-\mu \mathrm{l}$ volume onto the nares, approximately $20-\mu \mathrm{g}$ LPS per mouse), a dose that causes mild-moderate forms of ALI. To determine the therapeutic effect of cortistatin in the progression of $\mathrm{ALI}$, Cort+/+ mice were infused i.n. with LPS $\left(2-\mathrm{mg} \cdot \mathrm{kg}^{-1}\right.$ mouse, in $40-\mu \mathrm{l}$ volume, approximately 40- $\mu$ g LPS per mouse), an endotoxin dose that causes severe forms of $\mathrm{ALI}$, and then treated intraperitoneally $120 \mathrm{~min}, 24 \mathrm{~h}$ and $48 \mathrm{~h}$ later with vehicle or cortistatin $(1 \mathrm{nmol}$ per mouse, in 200- $\mu$ l volume, approximately $140-\mu \mathrm{g}$ cortistatin $\mathrm{kg}^{-1}$ mouse). Mice infused i.n. with saline, instead of LPS, were used as basal controls of reference. When indicated, cyclosomatostatin and [D-Lys ${ }^{3}$ ]-GHRP-6 were infused i.n. $(10 \mu \mathrm{g}$ per mouse, in $20-\mu \mathrm{l}$ volume onto the nares, approximately $500-\mu \mathrm{g} \cdot \mathrm{kg}^{-1}$ mouse) $30 \mathrm{~min}$ before every cortistatin injection. On different times after LPS or saline inhalation, animals were killed by carbon dioxide (in all cases, death was ensured by further exsanguination) and bronchoalveolar lavage fluid (BALF) and lungs were isolated and processed for analysis of leukocyte infiltration, cytokine contents, vascular permeability, histopathology and myeloperoxidase activity as described below.

\subsection{Induction of experimental lung fibrosis}

To investigate the effect of cortistatin deficiency in severity of lung fibrosis, bleomycin was administered intratracheally (at $1.8-\mathrm{U} \cdot \mathrm{kg}^{-1}$ mouse, in $50-\mu \mathrm{l}$ volume) to anaesthetized (i.p., ketamine $80 \mathrm{mg}$, xylazine $10-\mathrm{mg} \cdot \mathrm{kg}^{-1}$ mouse) Cort $+/+$, Cort $+/-$ and Cort-/- mice. When indicated, other doses of bleomycin (from 1.2- to $5-U \cdot \mathrm{kg}^{-1}$ mouse) were assayed (see Figure 5). To investigate the therapeutic effect of cortistatin in lung fibrosis, Cort $+/+$ mice were injected intratracheally with bleomycin $\left(3.2-U \cdot \mathrm{kg}^{-1}\right.$ mouse, in 50- $\mu$ l volume) and treated three times per week with vehicle or cortistatin via a local intranasal pathway (at 50-pmol cortistatin per mouse, in 20- $\mu$ l volume) or a systemic intraperitoneally pathway (at $1 \mathrm{nmol}$ cortistatin per mouse, in 200- $\mu$ l volume), starting immediately (protective acute regime) or 5 days (therapeutic regime) after bleomycin injection. Mice injected intratracheally with saline, instead of bleomycin, were used as basal controls of reference. When indicated, cyclosomatostatin and [D-Lys ${ }^{3}$ ]-GHRP-6 were infused i.n. (10 $\mu \mathrm{g}$ per mouse, in $20-\mu$ l volume onto the nares, approximately $500-\mu \mathrm{g} \cdot \mathrm{kg}^{-1}$ mouse) $30 \mathrm{~min}$ before every cortistatin injection. Survival and body weight were daily monitored for 3 weeks. On different times after bleomycin injection, animals were killed by carbon dioxide and BALFs and lungs were isolated and analysed for leukocyte infiltration, cytokine contents, vascular permeability, histopathological signs and fibrotic markers (collagen content and gene expression) as described below.

\section{6 | Histopathological analysis}

For histopathological evaluation, freshly collected lungs were fixed in $10 \%$ buffered formalin, embedded in paraffin and sectioned. Crosssections $(5-\mu \mathrm{m})$ were stained with haematoxylin/eosin (H\&E), with Masson's trichrome or with Picrosirius Red using standard techniques. Images were acquired in an Axio Scope.A1 microscope (Carl Zeiss, Germany) using $5 \times$ and $10 \times$ objectives and $10 \times$ ocular and analysed with Zen 2011 Light Edition software (Carl Zeiss). All histopathological analysis and determinations were performed in a blinded manner by at least two independent researchers in whole-lung sections. ALI-induced histopathology was scored in H\&E-stained lung sections determining the extent of inflammatory cell infiltration on alveolar walls, alveolar haemorrhage and alveolar septum congestion, using a semiquantitative scale from 0 (normal and no focal inflammatory infiltrates) to 4 (severe infiltration and damage in lung structure). Bleomycin-induced pulmonary fibrosis was scored in Masson's trichrome-stained lung sections according to a semiquantitative scale (0 to 4) evaluating alveolar thickness, damage of lung structure and fibrosis extension (Ashcroft et al., 1988):- 0, normal lung or minimal fibrous thickening of alveolar or bronchial walls, 1, moderate thickening of the wall, with less than $25 \%$ of fibrotic area, but without obvious damage to lung architecture, 2, formation of fibrous bands, fibrous masses in $25-50 \%$ of lung area, and definitive damage of lung structure, 3 , severe distortion of the structure and large fibrous areas ( $>50 \%$ of a cross-section involved) and 4 , total fibrous obliteration of the field. Results show the mean value of at least three nonoverlapping randomly selected areas per lung section (with $5 \times$ objective) and three representative sections per mouse (discarding at least $200 \mu \mathrm{m}$ between sections). 


\section{7 | Bronchoalveolar lavage fluid (BALF) collection and analysis}

A cannula (21G) was inserted into the trachea, and ice-cold PBS/100-mM EDTA $(0.8 \mathrm{ml})$ was instilled twice into the lung. BALF was harvested and centrifuged $\left(400 \mathrm{~g}, 8 \mathrm{~min}, 4^{\circ} \mathrm{C}\right)$. Cell pellets were resuspended in PBS and used to determine total cell numbers using a standard haemocytometer and to analyse the percentage of neutrophils, macrophages and T lymphocytes in BALF by flow cytometry as described below (Tager et al., 2008). Alternatively, cell populations were examined by counting at least 200 cells on Wright-Giemsa-stained BALF CytoSpin preparations. The supernatants collected from BALFs were used to determine the levels of cytokines and chemokines using sandwich ELISAs (see above for specific capture and biotinylated antibodies) following the manufacturer's recommendations, to measure total protein content using a BCA Protein Assay Kit (Pierce/Thermo Fisher) and to determine the levels of mouse albumin using an ELISA kit (Abcam, Cambridge, UK, cat\#ab207620).

\section{8 | Measurement of pulmonary myeloperoxidase activity}

Oxidative stress and neutrophil infiltration in the lung was also monitored by measuring myeloperoxidase activity by using a method reported previously (Gonzalez-Rey, Chorny, Varela, et al., 2006). In brief, left lung lobules were homogenized at $50 \mathrm{mg} \cdot \mathrm{ml}^{-1}$ in phosphate buffer $(50 \mathrm{mM}, \mathrm{pH}$ 6.0) with $0.5 \%$ hexadecyltrimethylammonium bromide. Samples were frozen, thawed three times and centrifuged (30,000 g, $20 \mathrm{~min})$. The supernatants were diluted at 1:30 with assay buffer consisting in $50-\mathrm{mM}$ phosphate buffer $\mathrm{pH} 6.0$ with $167-\mu \mathrm{g} \cdot \mathrm{ml}^{-1} \mathrm{o}$-dianisidine and $0.0005 \% \mathrm{H}_{2} \mathrm{O}_{2}$, and the colorimetric reaction was measured at $450 \mathrm{~nm}$ between 1 and $3 \min \left(\Delta A_{450}\right)$ in a spectrophotometer (VersaMax Microplate Reader, from Molecular Devices, San Jose, CA, USA). Myeloperoxidase activity per gram of wet lung was calculated as follows: $13.5 \times \Delta A_{450}$ / lung weight. The coefficient 13.5 was empirically determined such that $1-U$ myeloperoxidase activity is the amount of enzyme that will reduce $1 \mu \mathrm{mol} \mathrm{H}_{2} \mathrm{O}_{2} \min ^{-1}$.

\section{9 | Pulmonary macrophage cultures}

Pulmonary macrophages were enriched by plastic adherence (120 min at $37^{\circ} \mathrm{C}$, in 24-well plates) of BALFs collected from Cort $+/+$, Cort $+/-$ or Cort-/- mice $24 \mathrm{~h}$ after LPS-induced ALI. After washing and removal of nonadherent cells, the adherent macrophages $\left(5 \times 10^{4}\right.$ cells) were cultured in RPMI complete medium (RPMI-1640 supplemented with $10 \% \mathrm{FBS}, 100-\mathrm{U} \cdot \mathrm{ml}^{-1}$ penicillin/streptomycin, 2-mM L-glutamine and 50- $\mu \mathrm{M}$ 2-mercaptoethanol, all from Gibco/Thermo Fisher) in the absence (unstimulated) or presence (stimulated) of LPS $\left(0.5 \mu \mathrm{g} \cdot \mathrm{ml}^{-1}\right)$ and treated with or without cortistatin $(10 \mathrm{nM})$. After
$24 \mathrm{~h}$, the levels of TNF- $\alpha$ in culture supernatants were determined by ELISA.

\subsection{0 | Measurement of pulmonary vascular permeability}

Pulmonary vascular permeability was quantified by measuring albumin and protein contents in BALFs (see above) and using the Evans blue dye extravasation assay (Tager et al., 2008). Briefly, Evans blue dye (20 $\mathrm{mg} \cdot \mathrm{kg}^{-1}$ ) was injected through mouse tail vain $3 \mathrm{~h}$ before kill. At the time of killing, blood was collected into a heparinized syringe by cardiac puncture and mice were then perfused with PBS through the right ventricle to remove intravascular dye from the lungs. Lungs were dissected and homogenized, and Evans blue dye was extracted by the addition of $2 \mathrm{vol}$ of formamide followed by incubation overnight at $60^{\circ} \mathrm{C}$. After centrifugation ( $5000 \mathrm{~g}, 30 \mathrm{~min}$ ), the absorption of Evans blue in lung supernatants and plasma was measured at $620 \mathrm{~nm}$ and corrected for the presence of haem pigments as follows: $A_{620}-\left(1.426 \times A_{740}+0.030\right)$. We calculated an Evans blue index as the ratio of the amount of dye in the lungs to the plasma dye concentration. Pulmonary vascular permeability was also monitored through the ratio between lung weight measured immediately after its excision (wet weight) and lung weight after 5 days in an oven at $60^{\circ} \mathrm{C}$ (dry weight).

\subsection{1 | Flow cytometric analysis}

BALF cell pellets ( $10^{5}$ cells) were incubated with anti-mouse CD16/ CD32 antibody $\left(1: 100,4^{\circ} \mathrm{C}, 10 \mathrm{~min}\right)$ to avoid non-specific binding to Fc receptors and with 7-aminoactinomycin D (1:100, Calbiochem/ Sigma-Aldrich) to exclude dead cells. After washing in PBS/0.1\% BSA, cells were surface stained with fluorophore-conjugated antibodies for CD45 and for CD3, CD64 or Ly6G (each at 4-5 $\mu \mathrm{g} \cdot \mathrm{ml}^{-1}, 30 \mathrm{~min}, 4^{\circ} \mathrm{C}$ ) and were analysed in a FACSCalibur flow cytometer (BD Biosciences). Data were acquired until at least 20,000 events were collected from a live gate using forward/side scatter plots and 7-aminoactinomycin $D$ staining. Percentages of CD64+ macrophages, CD3+ T lymphocytes and $\mathrm{Ly} 6 \mathrm{G}+$ neutrophils were analysed in a gated CD45+ cell population using FlowJo v9 software (RRID:SCR_008520) and the differential number of each cell subpopulation in BALF was calculated by multiplying this percentage by the total number of collected BALF cells.

\subsection{2 | Immunofluorescence analysis of pulmonary myofibroblasts}

Formalin-fixed lung sections were incubated in 10-nM sodium citrate $/ 0.05 \%$ Tween $20\left(20 \mathrm{~min}, 100^{\circ} \mathrm{C}\right)$ for antigen retrieval, cooled in water and then incubated twice during $5 \mathrm{~min}$ in PBS/0.025\% Triton $\mathrm{X}-100$. Sections were blocked with $10 \%$ goat serum/1\% BSA 
$\left(120 \mathrm{~min}, 20^{\circ} \mathrm{C}\right)$ and incubated with primary anti- $\alpha \mathrm{SMA}$ antibody (diluted at 1:1000 in PBS/1\% BSA, overnight, $4^{\circ} \mathrm{C}$ ). After extensive washing with $\mathrm{PBS} / 0.025 \%$ Triton $\mathrm{X}-100$, sections were incubated with secondary Alexa Fluor 568-conjugated antibody (diluted at 1:1000 in PBS/1\% BSA, $60 \mathrm{~min}, 20^{\circ} \mathrm{C}$ ). Nuclei were DAPI counterstained (diluted at 1:1000 in PBS, $5 \mathrm{~min}, 20^{\circ} \mathrm{C}$ ) and sections were mounted in Mowiol. Sections in which we omitted primary antibody were used as negative controls, showing in all cases lack of fluorescence signal. Sections were examined in an Olympus IX81 fluorescence microscope (Olympus Life Science, Hamburg, Germany) and the images were acquired at $100 \times$ magnification (Olympus CellSens Imaging software) using the same parameters and region of interest (ROI) between samples and were quantified for the mean of fluorescence intensity using the Fiji ImageJ software. The Immuno-related procedures used comply with the recommendations made by the British Journal of Pharmacology (Alexander et al., 2018).

\subsection{3 | Measurement of collagen content in tissues}

The collagen content in lungs of mice was measured using the hydroxyproline assay (Reddy \& Enwemeka, 1996). Briefly, right lung lobes were hydrolysed in $6-\mathrm{N} \mathrm{HCl}$ (approximately $100 \mathrm{mg}$ tissue $\mathrm{ml}^{-1}$ ) at $95^{\circ} \mathrm{C}$ for $20 \mathrm{~h}$ and shaking. After centrifugation $\left(13,000 \mathrm{~g}, 15 \mathrm{~min}, 20^{\circ} \mathrm{C}\right)$, supernatants were diluted to reach a final concentration of $4-\mathrm{N} \mathrm{HCl}$, transferred to 96-well plates and oxidized with $1.2 \%$ chloramine-T/10\% propanol in citrate acetate buffer pH 6.5 (720-mM sodium acetate, 1\% acetic acid, 200-mM citric acid and $680-\mathrm{mM}$ sodium hydroxide) for $25 \mathrm{~min}$ at $20^{\circ} \mathrm{C}$ and shacking. Ehrlich's reagent ( $1 \mathrm{vol}, 15 \%$-dimethylaminobenzaldehyde in propanol/perchloric acid 2:1, vol:vol) was added to wells and incubated at $60^{\circ} \mathrm{C}$ during $1 \mathrm{~h}$. Absorbance at $550 \mathrm{~nm}$ was measured in a spectrophotometer and extrapolated to a standard hydroxyproline curve. Collagen content was calculated by multiplying the hydroxyproline measurements by 7.40 (a coefficient according to the fact that hydroxyproline represents $13.5 \%$ of amino acids in collagen sequence) and then expressed in $\mu$ g relative to the weight of tissue.

\subsection{Isolation and culture of primary fibroblasts}

Lung lobules were collected from Cort $+/+$ and Cort $+/$ - mice (10 weeks old) and mechanically dissected in small pieces using sterile scalpels. Tissue fragments were digested in DMEM/F12 medium (Gibco) supplemented with $100-U \cdot \mathrm{ml}^{-1}$ penicillin/streptomycin, 2-mM L-glutamine and 140-U.L $\mathrm{L}^{-1}$ Liberase (Thermolysin Low, from Roche, Basel, Switzerland) at $37^{\circ} \mathrm{C}$ with shaking. After $60 \mathrm{~min}$, digested tissues were centrifuged $\left(525 \mathrm{~g}, 5 \mathrm{~min}, 20^{\circ} \mathrm{C}\right)$ and cell pellets were washed three times with complete DMEM/F12 medium (supplemented with $15 \% \mathrm{FBS}, 100-\mathrm{U} \cdot \mathrm{ml}^{-1}$ penicillin/streptomycin and 2-mM L-glutamine) and then cultured in complete DMEM/F12 medium in $75-\mathrm{cm}^{2}$ Nunc flasks (Nunc/Thermo Fisher), at $37^{\circ} \mathrm{C}, 5 \%$ $\mathrm{CO}_{2}$. After 3-7 days of culture, medium was replaced by $\mathrm{MEM} \alpha$ complete medium (MEM $\alpha$ supplemented with $15 \% \mathrm{FBS}, 100-\mathrm{U} \cdot \mathrm{ml}^{-1}$ penicillin/streptomycin and 2-mM L-glutamine, all from Gibco) and adhered fibroblasts were cultured until $80 \%$ confluence, harvested by adding trypsin-EDTA solution (Sigma-Aldrich, cat\#T4049) and maintained at $5 \times 10^{5}$ cells per flask (in $175-\mathrm{cm}^{2}$ Nunc flasks) at $37^{\circ} \mathrm{C}, 5 \% \mathrm{CO}_{2}$ until their use. To evaluate gene expression by realtime $\mathrm{qPCR}, 4 \times 10^{4}$ fibroblasts were cultured in six-well Nunc plates, cultured until $80 \%$ confluence, synchronized to $G_{0}$ phase by incubation in free-FBS MEM $\alpha$ (overnight at $37^{\circ} \mathrm{C}, 5 \% \mathrm{CO}_{2}$ ) and then cultured in complete MEM $\alpha$ in the absence or presence of TGF- $\beta 1$ (10 ng. $\mathrm{ml}^{-1}$, PeproTech) for $24 \mathrm{~h}$. When indicated, cortistatin was added at $100 \mathrm{nM}$ to cultures simultaneously with TGF- $\beta 1$ stimulation. To evaluate Smad2/3 nuclear translocation by immunofluorescence analysis, $10^{3}$ fibroblasts were cultured until $80 \%$ confluence in glass coverslips, which were inserted in 24-well Nunc plates, synchronized and cultured in complete MEM $\alpha$ in the absence or presence of TGF- $\beta 1\left(10 \mathrm{ng} \cdot \mathrm{ml}^{-1}\right)$ for $60 \mathrm{~min}$. To evaluate protein expression by western blot, $5 \times 10^{5}$ fibroblasts were cultured in $75-\mathrm{cm}^{2}$ Nunc flasks until $80 \%$ confluence, synchronized and cultured in complete MEM $\alpha$ in the absence or presence of TGF- $\beta 1$ (10 $\mathrm{ng} \cdot \mathrm{ml}^{-1}$ ) for $24 \mathrm{~h}$.

Cell viability of fibroblast cultures was evaluated using Alamar Blue assay and ATP determinations. In brief, 1500 fibroblasts were seeded in 96-well plates, synchronized and cultured for different times and Alamar Blue reagent (10\% vol/vol, Sigma-Aldrich) was added during the last $4 \mathrm{~h}$ of the culture and measured its reduction by fluorescence (excitation $550 \mathrm{~nm} /$ emission $590 \mathrm{~nm}$ ) in a fluorescence plate reader (Tecan, Männedorf, Switzerland). Moreover, levels of ATP were determined using CellTiter-Glo Luminescent Cell Viability Assay kit (Promega, Madison, WI, USA) following manufacturer's instructions.

Migration of fibroblasts was determined using an in vitro wound healing assay. In brief, $10^{3}$ fibroblasts were seeded in Culture-Inserts 2 Well in $\mu$-Dish $35 \mathrm{~mm}$ (Ibidi, Gräfelfing, Germany) and then cultured to confluence. After cell synchronization, the inserts were removed and complete MEM $\alpha$ medium was added. At different time points, wells were observed in an Olympus microscope and images were acquired at $100 \times$ magnification under phase-contrast mode. The percentage of unhealed wound area was quantified using Fiji ImageJ software and the MRI Wound Healing Tool (http://dev.mri.cnrs.fr/projects/imagej-macros/wiki/ Wound_Healing_Tool).

\subsection{Immunofluorescence analysis of primary fibroblasts}

Lung fibroblasts were cultured in coverslips as described above and then fixed with $4 \%$ paraformaldehyde/2\% glucose during $15 \mathrm{~min}$ at $20^{\circ} \mathrm{C}$. After extensive washing with PBS, cells were incubated with $30-\mathrm{mM}$ glycine for $5 \mathrm{~min}$ and permeabilized with $0.1 \%$ 
Triton X-100 (15 min, $\left.20^{\circ} \mathrm{C}\right)$. Coverslips were blocked with PBS/5\% FBS $/ 0.3 \%$ Triton $X-100\left(60 \mathrm{~min}, 20^{\circ} \mathrm{C}\right)$ and incubated with primary anti-Smad2/3 antibody (diluted at 1:200 in PBS/1\% BSA $/ 0.3 \%$ Triton X-100, overnight, $4^{\circ} \mathrm{C}$ ). After extensive washing with PBS/0.025\% Triton X-100, samples were incubated with secondary Alexa Fluor 488-conjugated antibody $\left(60 \mathrm{~min}, 20^{\circ} \mathrm{C}\right.$, diluted at $1: 1000$ in $\mathrm{PBS} / 1 \% \mathrm{BSA} / 0.3 \%$ Triton $\mathrm{X}-100)$. Nuclei were DAPI counterstained (1:500 in PBS, $5 \mathrm{~min}, 20^{\circ} \mathrm{C}$ ) and were mounted in Mowiol. Samples in which we omitted the primary antibodies were used as negative controls, showing in all cases lack of fluorescence signal. Samples were examined in an Olympus IX81 fluorescence microscope and the images were acquired at $400 \times$ magnification (Olympus CellSens Imaging software) using the same parameters and ROI for five independent experiments (in duplicates), and fluorescence intensity (integrated density) located specifically in nuclei was determined using the Fiji ImageJ software. At least a mean of 200 nuclei per experiment was quantified in a blinded fashion in each experimental group. Experimental details of immunofluorescence analysis conform to BJP guidelines (Alexander et al., 2018).

\subsection{6 | Determination of gene expression by real- time PCR}

Total RNA was isolated from lung lobes by tissue homogenization (Ultra-Turrax T-25, from IKA, Staufen, Germany) at 13,500 rpm for $40 \mathrm{~s}$ in TriPure reagent (Roche), following the manufacturer' protocol. Fibroblasts were cultured and activated as described above and then directly collected from culture plates by adding TriPure solution. Precipitated RNA ( $1 \mu \mathrm{g}$ ) was treated with DNase I (1 U) and then reversed transcribed using RevertAid First Strand cDNA Synthesis Kit (200 U, Thermo Fisher) and random hexamer primers $(5 \mu \mathrm{M})$ at $42^{\circ} \mathrm{C}$ for $60 \mathrm{~min}$ in a Mastercycler EP Gradient Thermocycler (Eppendorf, Madrid, Spain). SYBER green quantitative PCR (SensiFast Sybr NoRox mix, from Bioline, Germany) was performed on the CFX96 RealTime PCR system (Bio-Rad, Hercules, CA, USA) using the following conditions: $94^{\circ} \mathrm{C}$ for $5 \mathrm{~min}$ followed by 40 cycles at $94^{\circ} \mathrm{C}$ for $30 \mathrm{~s}$, annealing at $60^{\circ} \mathrm{C}$ for $30 \mathrm{~s}$ and extension at $72^{\circ} \mathrm{C}$ for $30 \mathrm{~s}$. Primer sequences for cortistatin, $\alpha \mathrm{SMA}$, connective tissue growth factor (CTGF), collagen $1 \alpha 2$ (Col1a2), fibronectin (FN) and Ribosomal Protein Lateral Stalk Subunit PO (RPLPO) were (5' to $\left.3^{\prime}\right)$ : Cort forward, GCCTT CTGACTTTCCTTGCC; Cort reverse, GAAAGCTCCCCGCTGATTGA; $\alpha$ SMA forward, CAGGGAGTAATGGTTGGAAT; $\alpha$ SMA reverse, TCTC AAACATAATCTGGGT; CTGF forward, AGAACTGTGTACGGAGCGT G; CTGF reverse, GTGCACCATCTTTGGCAGTG; Col1a2 forward, TC TCCTGGAAATGTTGGCCCATCT; Col1a2 reverse, AATCCGATGTTG CCAGCTTCACCT; FN forward, GACCCTTACACGGTTTCCCA; FN reverse, TCATCCGCTGGCCATTTTCT; RPLPO forward, TGCACTCTC GCTTTCTGGAG; and RPLPO reverse, CTGACTTGGTTGCTTTGGCG. The expression of each gene was normalized against the expression of the housekeeping gene RPLPO in every PCR reaction and estimating fold-change expression with delta-delta $\mathrm{Ct}$ method.

\subsection{Western blot analysis of fibroblast cultures}

Mouse pulmonary fibroblasts were cultured and activated as described above and then lysed by incubation with lysis buffer containing 50-mM Tris- $\mathrm{HCl}$ pH 7.4, 150-mM NaCl, 1-mM EDTA, 1\% Triton $\mathrm{X}-100,1 \%$ sodium deoxycholic acid, $0.1 \% \mathrm{SDS}, 10-\mu \mathrm{g} \cdot \mathrm{ml}^{-1}$ protease inhibitor cocktail (cat\#P8465) and phosphatase inhibitor (PhosSTOP, from Roche) for $2 \mathrm{~h}$ at $4^{\circ} \mathrm{C}$ and shaking. Lysates were centrifuged $\left(21,000 \mathrm{~g}, 15 \mathrm{~min}, 4^{\circ} \mathrm{C}\right)$ and supernatants containing protein extracts $(10 \mu \mathrm{g})$ were separated on $12 \%$ SDS-PAGE and blotted onto PVDF membranes (ImmMobilon-FL PVDF, Millipore/Thermo

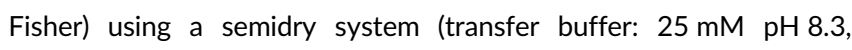
192-mM glycine and 20\% methanol). Membranes were blocked with TBS-T buffer (10-mM Tris, 150-mM NaCl, pH 7.5 and 0.1\% Tween 20) and $5 \% \mathrm{BSA}$ for $1 \mathrm{~h}$ at $20^{\circ} \mathrm{C}$ and subsequently probed overnight at $4^{\circ} \mathrm{C}$ with pairs of primary antibodies directed against Akt and phospho-Akt, p38 MAPK and phospho-p38 MAPK, or phosphoERK1/2 and ERK1/2 (diluted at 1:1000 in TBS-T/2\% BSA). Immunodetection of primary antibodies was performed by incubation with secondary antibodies labelled to the near-IR fluorophores IRDye $800 \mathrm{CW}$ (green dye, for phosphorylated kinases) or IRDye 680RD (red dye, for nonphosphorylated kinases) diluted at 1:20,000 in TBS-T/2\% BSA $/ 0.02 \%$ SDS for $1 \mathrm{~h}$ at $20^{\circ} \mathrm{C}$. Images of blots were acquired in an Odyssey CLx (LI-COR Biosciences) and fluorescence intensities of specific bands corresponding to phosphorylated and nonphosphorylated (used to normalize protein expression) forms of each kinase were quantified using Fiji ImageJ software. Experimental details of western blot analysis conform to BJP guidelines (Alexander et al., 2018).

\subsection{8 | Data and statistical analysis}

All experiments are randomized and blinded. All data are expressed as mean $\pm S D$, unless when specified (i.e. Figure 6). To control for unwanted sources of variation between individual experiments, data obtained from qPCR and western blot analysis of fibroblast cultures (Figure 6b,c,e) were normalized to the mean of unstimulated Cort+/+ fibroblasts. No data were excluded and outliers were included in data analysis and presentation. Group size is the number of independent animals or cell cultures, and statistical analysis was performed using these independent values. The data and statistical analysis comply with the recommendations of the British Journal of Pharmacology on experimental design and analysis in pharmacology (Curtis et al., 2018). In accordance with journal policy, statistical analysis was performed only when a minimum of $n=5$ independent samples was acquired. We analysed data for statistical differences between groups using the unpaired Student's $t$-test or the non-parametric Mann-Whitney $U$ test and. Post hoc tests were conducted only if $F$ in ANOVA achieved $P<0.05$. Survival curves were analysed by the Kaplan-Meier log-rank test. All analyses were performed using GraphPad Prism v5.0 software (La Jolla, CA, USA, RRID:SCR_002798). We considered $P$ values $<0.05$ (two tailed) as significant. 


\subsection{Nomenclature of targets and ligands}

Key protein targets and ligands in this article are hyperlinked to corresponding entries in the IUPHAR/BPS Guide to PHARMACOLOGY http://www.guidetopharmacology.org and are permanently archived in the Concise Guide to PHARMACOLOGY 2019/20 (Alexander et al., 2019).

\section{3 | RESULTS}

\section{1 | Protective role of cortistatin in bacterial endotoxin-induced $\mathrm{ALI}$}

We first investigated the role played by cortistatin in pulmonary inflammation by using a well-characterized experimental model of AL that is induced in mice by intranasal injection of the bacterial endotoxin LPS, which mirrors important aspects of human ARDS and is widely used to assay novel therapeutic agents (Tsushima et al., 2009). Pulmonary administration of LPS $\left(2 \mathrm{mg} \cdot \mathrm{kg}^{-1}\right)$ caused a rapid influx of circulating inflammatory cells, mainly of neutrophils, into the alveolar spaces (Figure 1a), which was accompanied by excessive levels of inflammatory cytokines and chemokines (Figure 1b) and resulted in enhanced permeability of pulmonary capillaries, alveolar protein leakage and interstitial oedema (Figure 1c). Histopathological analysis of H\&E-stained lung sections confirmed that pulmonary infusion of LPS resulted in marked damage in lung structure, including substantial inflammatory cell infiltration, abundant alveolar exudation and disseminated haemorrhages, indicating the occurrence of ALI (Figure 1d). We observed that the systemic administration of cortistatin ameliorated the severity of $\mathrm{ALI}$, as denoted by a significant reduction in leukocyte infiltration, lung inflammation, interstitial and alveolar oedema, and the histopathological signs (Figure 1a-d). Moreover, macrophages isolated from BALFs of mice with LPS-induced ALI that were treated with cortistatin produced less inflammatory factors than those isolated from untreated mice (Figure 1e). In this sense, ex vivo treatment with cortistatin significantly reduced the production of inflammatory cytokines by macrophages isolated from BALF of mice with ALI (Figure 1f). These data suggest that cortistatin impairs the acute inflammatory cascade induced by exposition to bacterial endotoxins in the lung and avoid subsequent disruption of epithelial integrity.

In order to investigate the ability of endogenous cortistatin to regulate pulmonary inflammation, we induced $A L I$ in mice that partially (Cort+/-) or fully (Cort-/-) lack the cortistatin gene. Infusion of LPS at low dose $\left(1 \mathrm{mg} \cdot \mathrm{kg}^{-1}\right)$ resulted in mild signs of ALI in wild-type mice, whereas caused exacerbated development of ALI in mice with a total, and even with a partial, deficiency in cortistatin (Figure 2). In comparison with wild-type mice (Cort $+/+$ ), we observed excessive leukocyte infiltration (Figure 2a), severe histopathological signs of pulmonary inflammation, oedema and damage (Figure $2 b$ ), and enhanced presence of inflammatory mediators (Figure $2 c$ ) and protein leakage (Figure 2d) in BALFs of Cort+/- and Cort-/- mice. Moreover, pulmonary macrophages isolated from Cort+/- and Cort-/- mice with ALI significantly produced more inflammatory TNF- $\alpha$ than macrophages isolated from BALF of Cort $+/+$ mice (Figure 2e). Importantly, exogenous administration of cortistatin to Cort + / - mice reversed the severe ALI phenotype that we observed in these animals (Figure 3). Moreover, in vitro treatment with cortistatin impaired the enhanced TNF- $\alpha$ production by BALF macrophages isolated from Cort $+/$ - and Cort-/- mice with ALI (Figure 2e). These findings indicate that a partial deficiency of cortistatin predisposes to develop exacerbated acute pulmonary inflammatory responses and severe lung damage after exposition to bacterial endotoxins.

\subsection{Deficiency in cortistatin exacerbates pulmonary fibrosis in bleomycin-challenged mice}

We further investigated the role played by cortistatin in a wellcharacterized model of pulmonary fibrosis induced by intratracheal injection of bleomycin, which shares significant similarities with human idiopathic pulmonary fibrosis (IPF) and has been widely used for studying pulmonary fibrogenesis and evaluating the effect of therapeutic antifibrotic strategies (Kolb et al., 2020). In this model, as occurred with exposition to infection, toxins or radiation, the antineoplastic drug bleomycin causes alveolar epithelial injury that induces the release of profibrotic cytokines/growth factors (i.e. TGF- $\beta 1$, TNF$\alpha$ and (TGF), which activate lung fibroblasts and their subsequent transformation into $\alpha \mathrm{SMA}$-expressing myofibroblasts that are responsible of the excessive extracellular matrix protein deposition that characterizes the fibrotic lung. We first found that mice lacking cortistatin showed significantly earlier and higher mortality after bleomycin challenge, relative to wild-type animals (Figure 4). Significant was the fact that bleomycin at doses as low as $1.2-1.8 \mathrm{U} \cdot \mathrm{kg}^{-1}$, which did not compromise survival of Cort $+/+$ mice, increased the mortality rate above $50 \%$ in Cort +/ - and Cort-/ - mice. In order to investigate the clinical markers and mechanisms involved in this susceptibility to bleomycin, we further used a dose of $1.8 \mathrm{U} \cdot \mathrm{kg}^{-1}$. Exposure of Cort $+/$ - and Cort-1- mice to this dose of bleomycin resulted in a significant loss of body weight (up to 20\%) and death rates ranging from $75 \%$ to $80 \%$ (Figure 5a). Histopathological examination of Masson's trichromestained pulmonary sections showed that, whereas lungs of bleomycinchallenged Cort $+/+$ mice had moderate thickening of the alveolar walls, less than $25 \%$ of fibrotic area and no obvious damage in lung architecture, mice that are partially or fully deficient in cortistatin had lungs with large fibrous areas (above 60\%), in many cases with total fibrous obliteration of the field, showing severe distortion of pulmonary structure (Figure $5 \mathrm{~b}$ ). We observed this increased fibrosis score in cortistatin-deficient mice as early as 7 days after bleomycin instillation, coinciding with the drop in survival (Figure 5a,b). Moreover, the exacerbated bleomycin-induced lung fibrosis observed in Cort+/and Cort-/- mice was accompanied by an excessive early leukocyte infiltration (mainly composed by neutrophils and macrophages) and increased levels of inflammatory mediators (Figure 5c). Moreover, deficiency in cortistatin increased pulmonary vascular leak after 

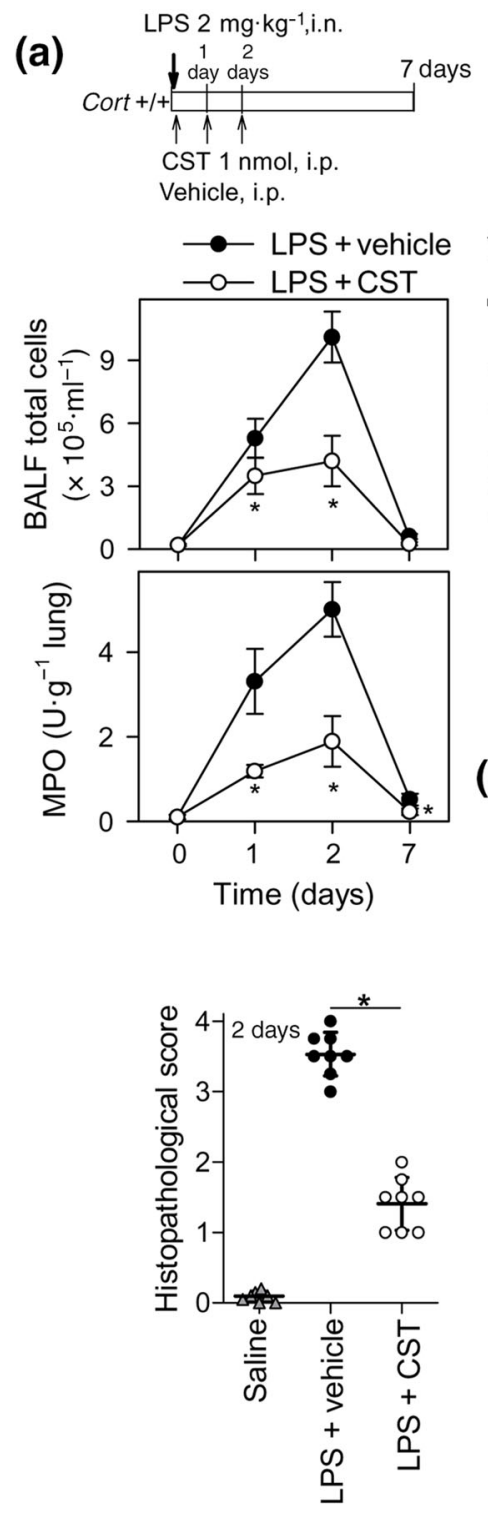

(b)

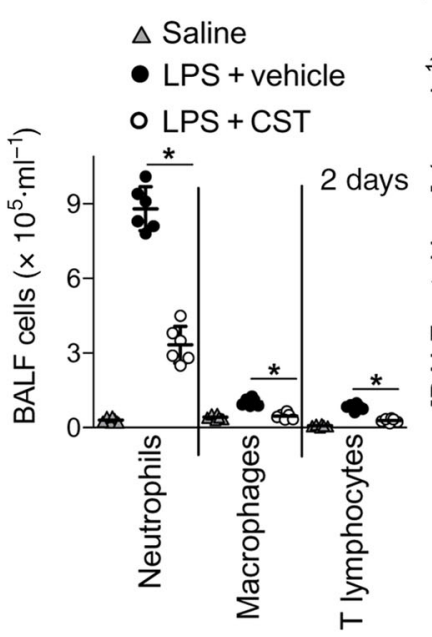

(d)

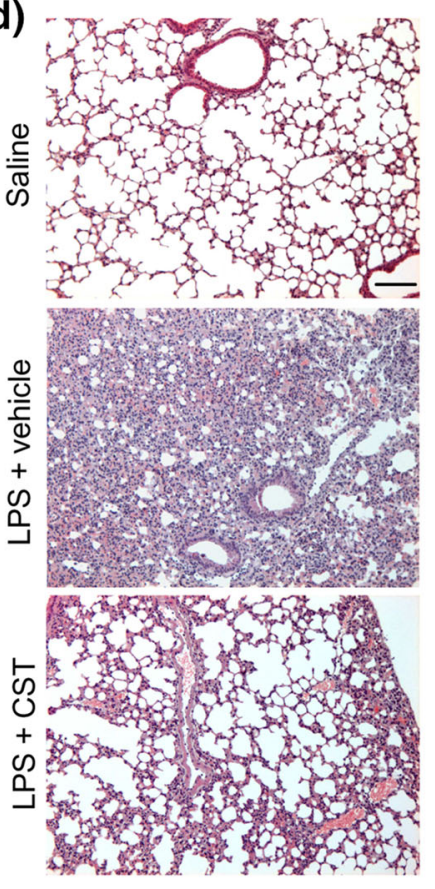

$\triangle$ Saline

- LPS + vehicle
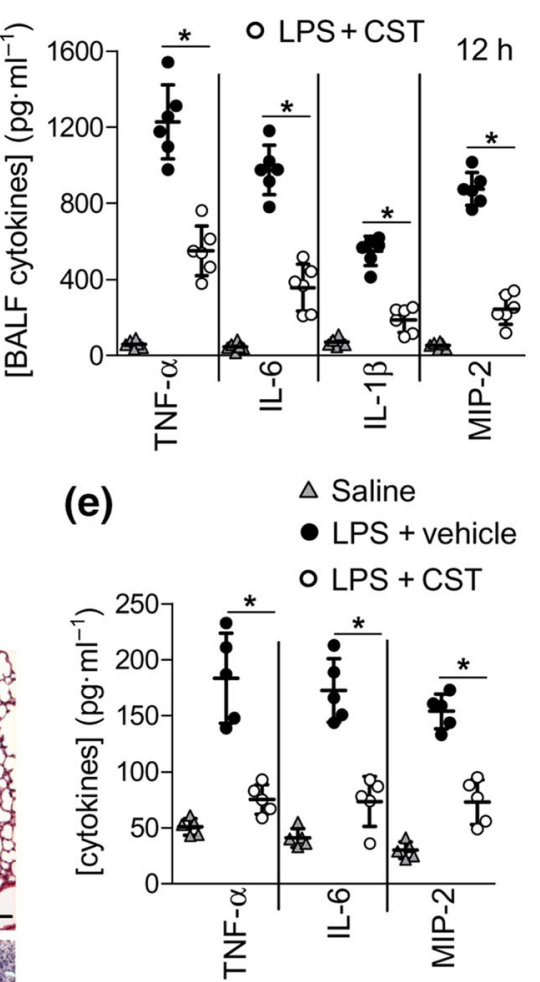

(f) $\quad \mathrm{TNF}-\alpha \quad \mathrm{IL}-6$

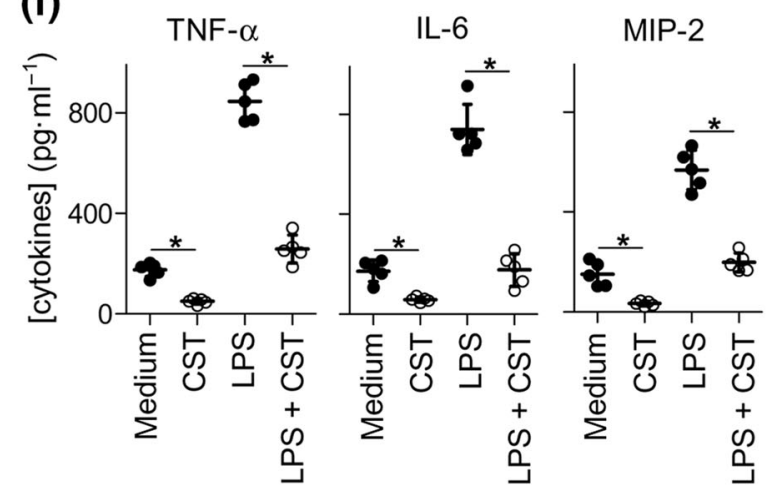

(c)

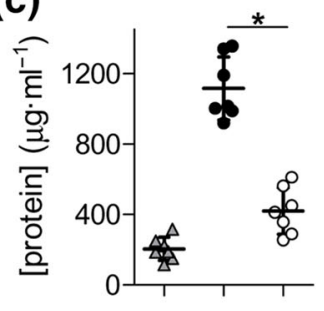

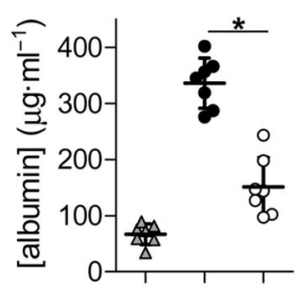

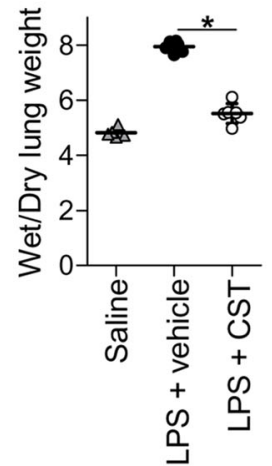

FIGURE 1 Treatment with cortistatin (CST) ameliorates acute lung injury (ALI). (a) Mice with LPS-induced ALI were treated intraperitoneally with vehicle or cortistatin (LPS + CST) as described in the scheme. Animals treated intranasally (i.n.) with saline were used as basal controls. The number of total cells and leukocyte subpopulations in bronchoalveolar lavage fluid (BALF) was determined at the indicated times.

Myeloperoxidase (MPO) activity in lung extracts was determined to confirm the presence of neutrophils. $n=8$ mice per group. (b) Cytokine contents in BALF isolated $12 \mathrm{~h}$ after LPS-induced ALI ( $n=6$ mice per group). (c) Lung oedema was determined by measuring protein and albumin contents in BALFs and wet/dry weight ratios of lungs isolated $48 \mathrm{~h}$ after LPS-induced ALI ( $n=7$ mice per group). (d) Histopathological scores were determined in H\&E-stained sections of lungs collected $48 \mathrm{~h}$ after LPS-induced ALI ( $n=8$ mice per group, scale bar: $100 \mu \mathrm{m})$.

(e) Spontaneous production of inflammatory cytokines by macrophages isolated from BALFs recovered $48 \mathrm{~h}$ after LPS-induced ALI ( $n=5$ mice per group, each by duplicated cell cultures). (f) Cytokine production by BALF macrophages collected 2 days after LPS-induced ALI and restimulated ex vivo with medium or LPS in the absence or presence of CST ( $n=5$ mice per group, each by duplicated cell cultures). Results are the mean \pm SD with dots representing individual values of biologically independent animals. ${ }^{*} P<0.05$ versus LPS + vehicle

bleomycin-induced injury, as indicated by elevated total protein content in BALFs and Evans blue extravasation in lungs of Cort $+/$ - and Cort-/ - mice in comparison with Cort $+/+$ mice (Figure 5d). Finally, we observed that bleomycin challenge resulted in marked enhancement of fibrotic markers and fibrogenic mediators in mice lacking cortistatin. Thus, collagen contents, TGF- $\beta 1$ levels and gene expression of CTGF were significantly elevated in lungs and BALFs collected from Cort+/ - and Cort-/ - mice 7-10 days after bleomycin instillation (Figure $5 \mathrm{c}, \mathrm{e}$ ). Moreover, immunofluorescence analysis of lung sections showed that deficiency in cortistatin significantly increased 
(a)

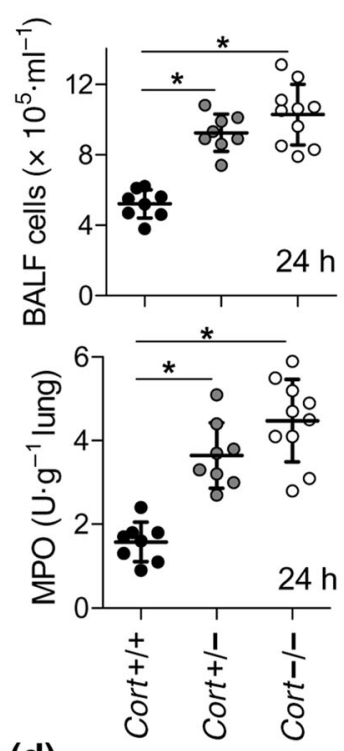

(d)

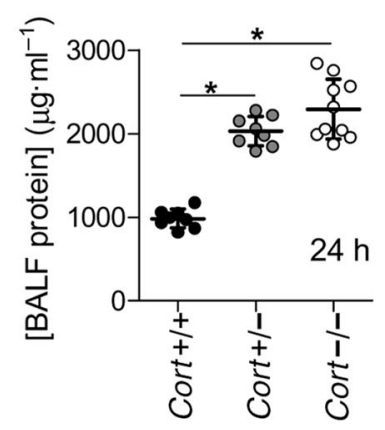

(b)

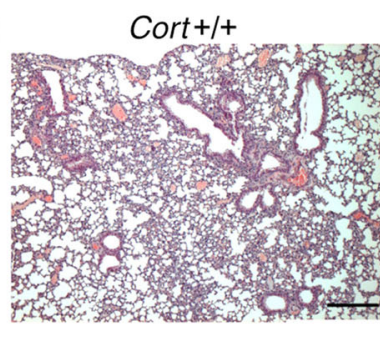

Cort-I-

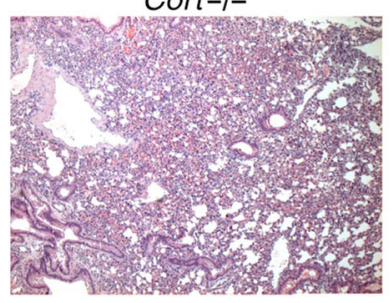

(e)

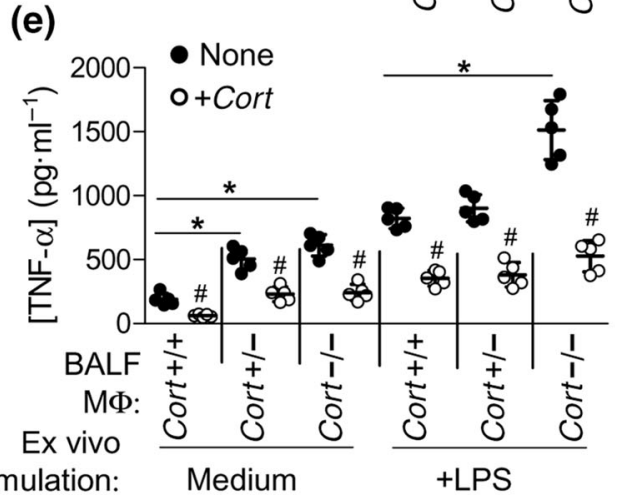

Cort+/-
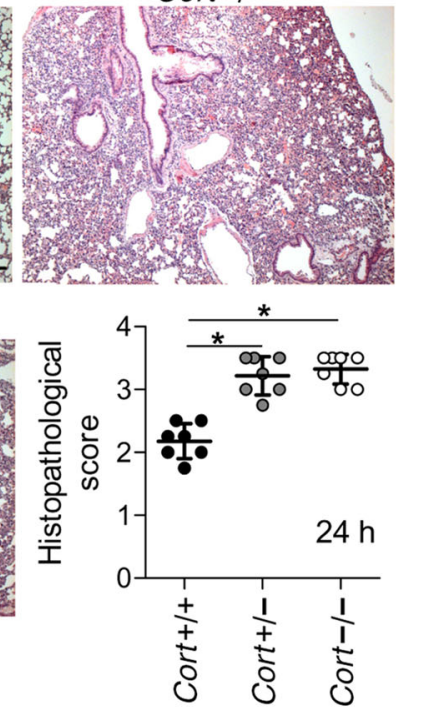

$24 \mathrm{~h}$ (c) $\quad$ Cort+l+

- Cort+l-

- Cort-/-

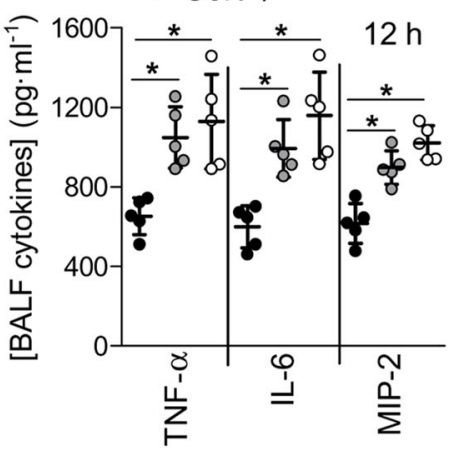

FIGURE 2 Deficiency in cortistatin exacerbates severity of acute lung injury (ALI) and pulmonary inflammation. ALI was induced in wild-type $($ Cort $+/+)$, partially deficient (Cort $+/-$ ) or totally deficient (Cort-/-) mice for cortistatin by intranasal instillation of LPS (1 mg.kg $\left.{ }^{-1}\right)$. (a) The number of total cells in bronchoalveolar lavage fluids (BALFs) and myeloperoxidase (MPO) activity in lung extracts was determined in samples isolated $24 \mathrm{~h}$ after LPS inhalation. $n=10$ mice per group. (b) Histopathological scores were determined in H\&E-stained lung sections isolated $24 \mathrm{~h}$ after LPS-induced ALI ( $n=7$ mice per group, scale bar: $200 \mu \mathrm{m}$ ). (c) Cytokine contents in BALF collected $12 \mathrm{~h}$ after LPS-induced ALI ( $n=5$ mice per group). (d) Lung oedema was assayed by measuring the protein contents in BALFs collected $48 \mathrm{~h}$ after LPS-induced ALI ( $n=7-10 \mathrm{mice}$ per group). (e) Production of inflammatory TNF- $\alpha$ by macrophages isolated from BALFs collected from Cort $+/+$, Cort $+/-$ or Cort $-/-$ mice $24 \mathrm{~h}$ after LPS-induced ALI and ex vivo restimulated with medium or LPS in the absence (none, open circles) or presence (closed circles) of cortistatin ( $n=5$ mice per group, each by duplicated cell cultures). Results are the mean \pm SD with dots representing individual values of biologically independent animals. ${ }^{*} P<0.05$ versus Cort $+/+$ mice. ${ }^{\#} P<0.05$ versus untreated macrophages in (e)

the presence of $\alpha \mathrm{SMA}$-expressing myofibroblasts in peribronchiolar and parenchymal areas of dense fibrotic remodelling at 3 weeks after bleomycin challenge (Figure 5e). All together, these findings indicate that cortistatin is a key regulator of pathological pulmonary fibrosis induced by tissue damage agents and that these effects are probably exerted both by indirectly limiting pulmonary inflammation and by directly impairing fibrogenic responses.

\section{3 | Cortistatin-deficient fibroblasts show increased fibrogenic responses}

To investigate whether endogenous cortistatin directly regulates fibrosis, independently of its immunoregulatory effects, we evaluated the fibrogenic responses of primary pulmonary fibroblasts isolated from wild-type and cortistatin-deficient mice. Because in vivo experiments demonstrated that partially deficient and totally deficient mice for cortistatin showed similar exacerbated pulmonary fibrosis in response to bleomycin, and as individuals with partial deficiency in this neuropeptide will be more frequent within the human population than those fully deficient, we focused in vitro experiments on Cort+/ - fibroblasts. First, we confirmed that mouse lungs and pulmonary fibroblasts expressed cortistatin (Figure 6a). Interestingly, activation of pulmonary fibroblasts with TGF- $\beta 1$ almost completely inhibited cortistatin gene expression and bleomycin challenge moderately reduced its expression in lungs (Figure 6a). Cort+/- pulmonary fibroblasts expressed significantly higher levels of the profibrogenic factor CTGF and the myofibroflastic marker $\alpha \mathrm{SMA}$ than Cort $+/+$ 
FIGURE 3 Administration of cortistatin (CST) reverses the exacerbated acute lung injury (ALI) phenotype showed by cortistatin-deficient mice. ALI was induced in partially deficient mice for cortistatin gene (Cort+/-) by intranasal infusion of LPS and then treated intraperitoneally with vehicle or cortistatin. Histopathological scores were determined in H\&E-stained lung sections ( $n=6$ mice per group, scale bar: $200 \mu \mathrm{m}$ ) and leukocyte infiltration, protein and cytokine contents were determined in bronchoalveolar lavage fluids (BALFs) isolated $24 \mathrm{~h}$ after LPSinduced ALI ( $n=7$ mice per group). Dashed grey horizontal lines correspond to values obtained from LPS-infused Cort $+/+$ mice. Results are the mean \pm SD with dots representing individual values of biologically independent animals. ${ }^{*} P<0.05$ versus vehicle-treated Cort $+/-$ mice

FIGURE 4 Deficiency in cortistatin gene significantly increases the mortality in experimental lung fibrosis. Pulmonary fibrosis was induced by intratracheal injection of different doses of bleomycin in wild-type (containing the cortistatin gene Cort $+/+$ ), partially deficient (Cort + /-) or totally deficient (Cort-/-) mice for cortistatin, and survival was daily monitored. Each panel includes the number of mice that were used per group. ${ }^{*} P<0.05$ versus Cort $+/+$ mice
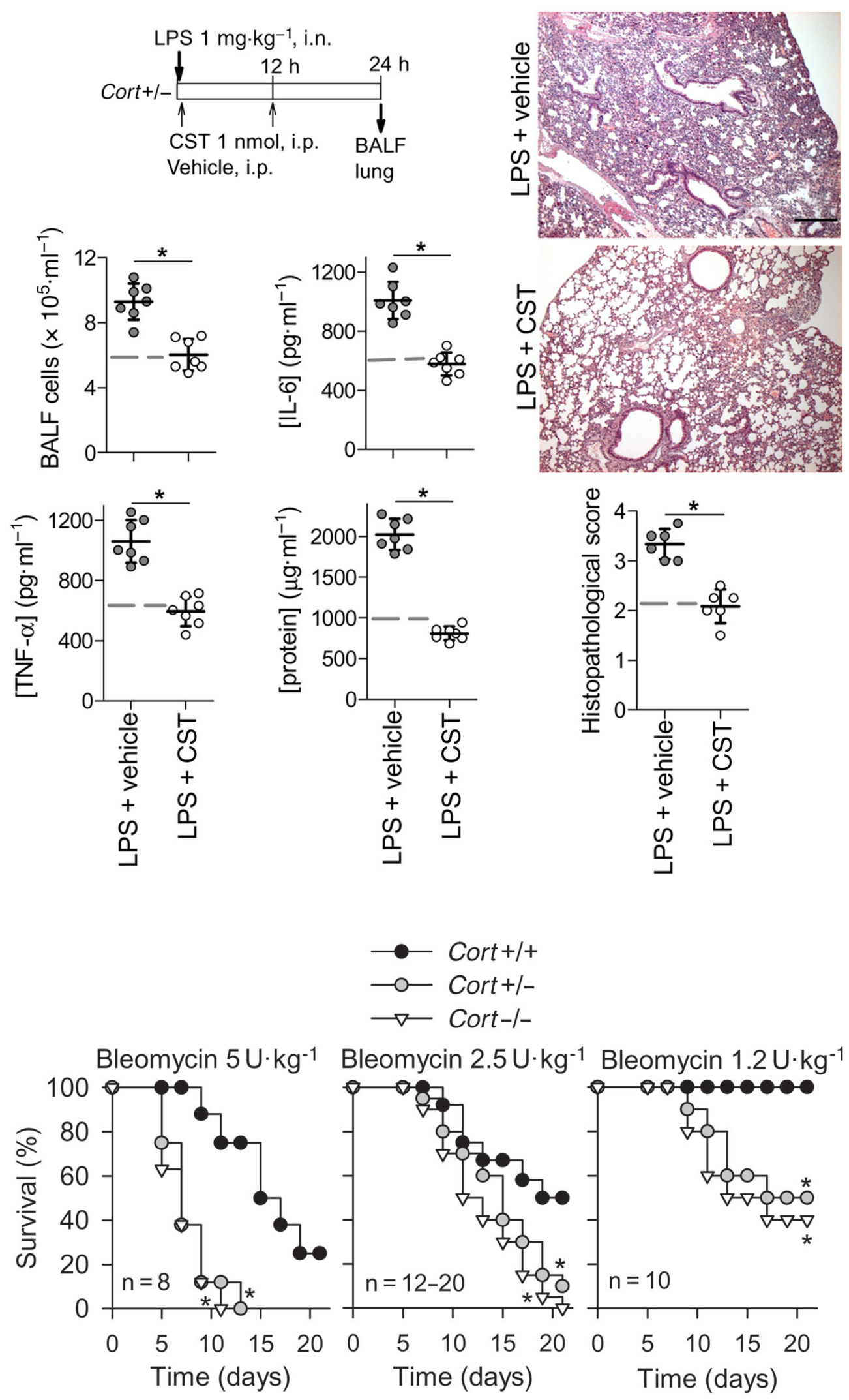

fibroblasts (Figure 6b). Interestingly, deficiency in cortistatin generated a fibroblast that, in basal conditions, expressed CTGF levels comparable with those expressed by TGF- $\beta 1$-activated Cort $+/+$ fibroblasts (Figure 6b), suggesting the existence of an overactivated state in cortistatin-deficient fibroblasts. The fibrogenic phenotype found in Cort+/- pulmonary fibroblasts correlated with the hyperactivation of various intracellular factors that are critically involved in profibrogenic signalling (Wynn, 2011; Wynn \& Ramalingam, 2013). 
(a) Bleo $1.8 \mathrm{U} \cdot \mathrm{kg}^{-1}$

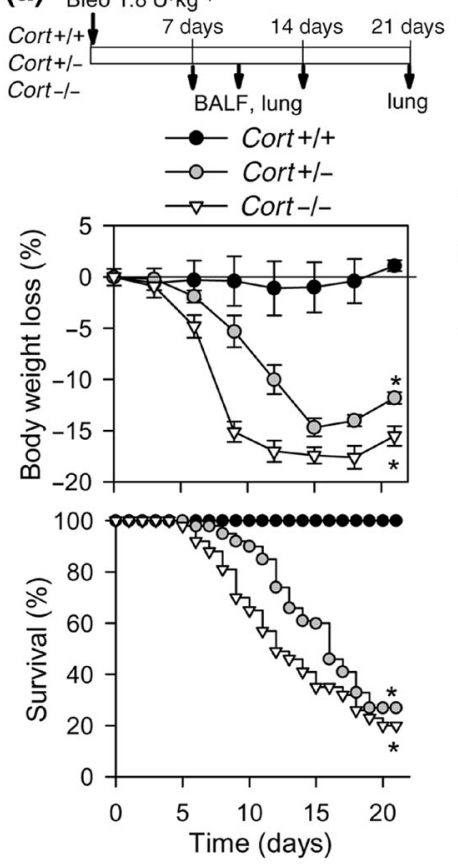

(c)

$$
\begin{aligned}
& \longrightarrow \text { Cort }+/+ \\
& \multimap-\text { Cort }+/- \\
& \rightarrow-\text { Cort }-1-
\end{aligned}
$$
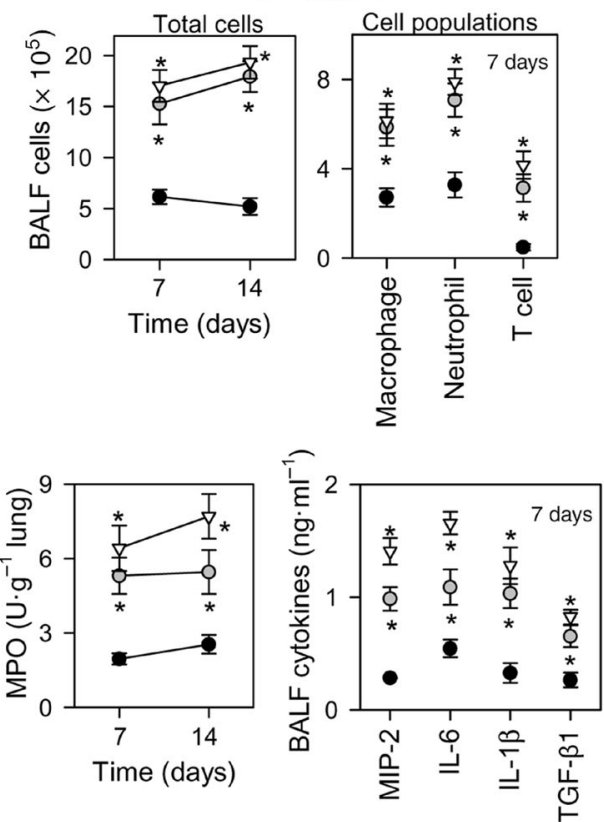
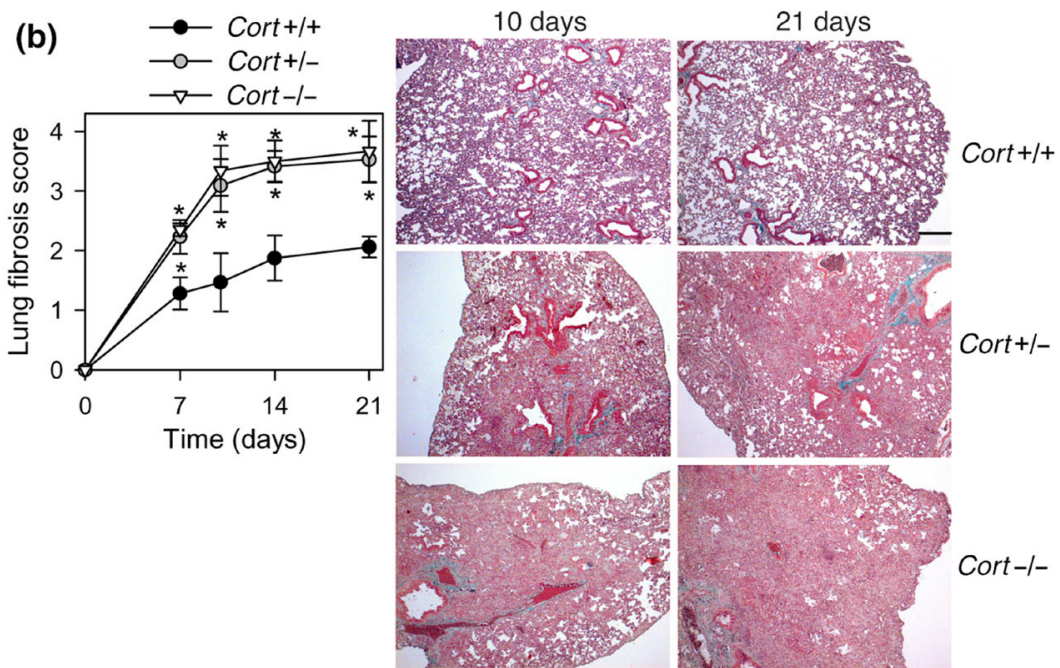

(d)
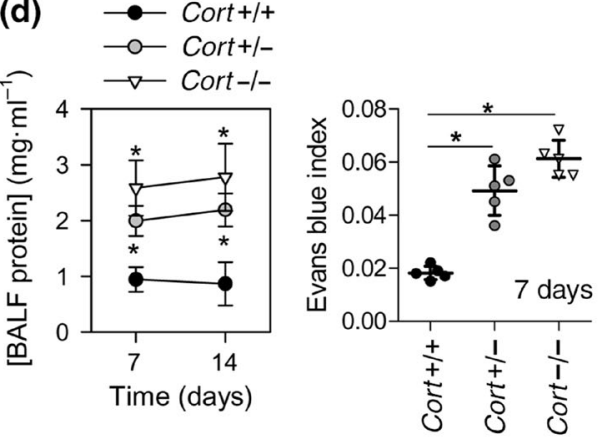

(e)
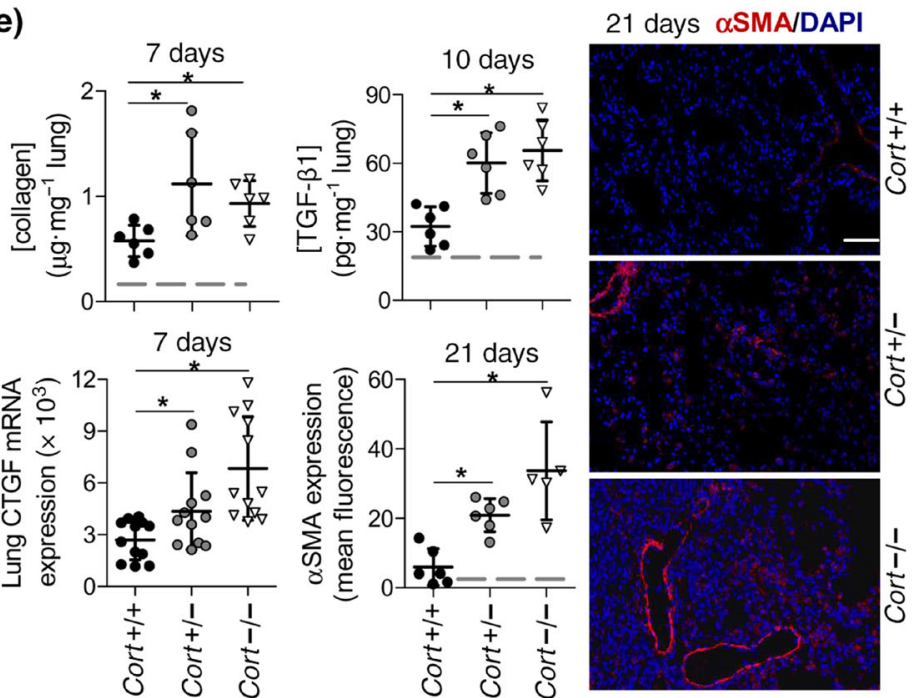

FIG URE 5 Deficiency in cortistatin increases the severity in an experimental model of lung fibrotic disease. Pulmonary fibrosis was induced by intratracheal injection of bleomycin $\left(1.8 \mathrm{U} \cdot \mathrm{kg}^{-1}\right)$ in wild-type (contain the cortistatin gene Cort $+/+$ ), partially deficient (Cort+/-) or totally deficient (Cort-/-) mice for cortistatin. (a) Body weight loss ( $n=10$ mice per group) and survival ( $n=28$ Cort $+/+, n=42$ Cort $+/-$ and $n=40$ Cort-/-) were daily monitored. (b) Pulmonary fibrosis scores were determined at the indicated times after bleomycin injection in Masson's trichrome-stained lung sections ( $n=8$ mice per group, unless six mice per group at Day 14, scale bar: $200 \mu \mathrm{m}$ ). (c) The number of total cells, macrophages, neutrophils and T lymphocytes in bronchoalveolar lavage fluids (BALFs) $(n=8$ mice per group), myeloperoxidase (MPO) activity in lung extracts ( $n=6$ mice per group) and BALF cytokine contents ( $n=6$ mice per group) were determined at the indicated times. (d) Lung oedema was determined by measuring protein contents in BALFs ( $n=8$ mice per group) and Evans blue extravasation index in lungs ( $n=5$ mice per group) isolated at the indicated times. (e) Markers of lung fibrosis were determined at the indicated times by measuring collagen contents and TGF- $\beta 1$ levels in lung protein extracts ( $n=6$ mice per group), CTGF mRNA expression in lungs ( $n=12$ mice per group) and $\alpha$ SMA-positive immunofluorescence in lung sections ( $n=5-6$ mice per group, scale bar: $100 \mu \mathrm{m}$ ). Dashed horizontal lines correspond to values obtained from naïve mice $(n=6)$. Results are the mean \pm SD with dots representing individual values of biologically independent animals. ${ }^{*} P<0.05$ versus Cort $+/+$ mice 
(a)
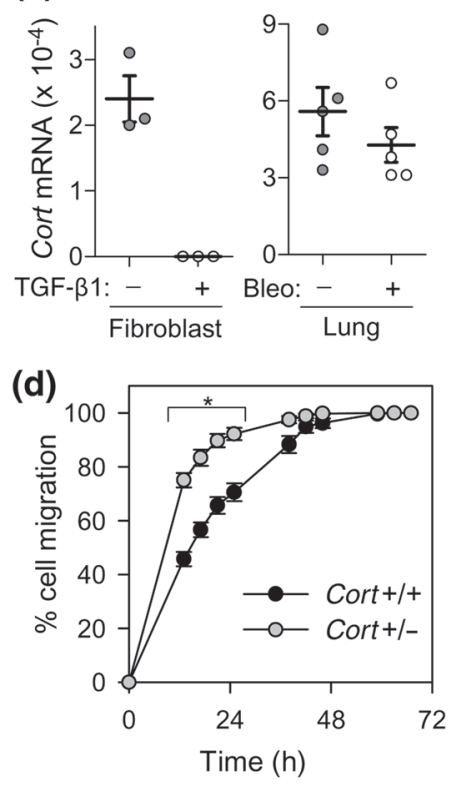

(e)

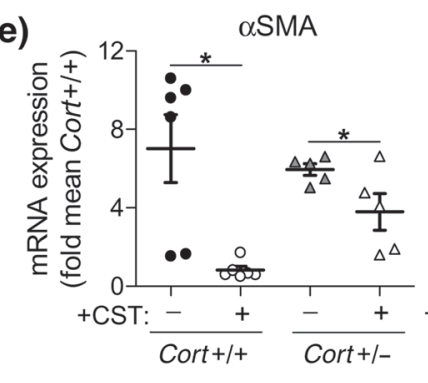

(b)

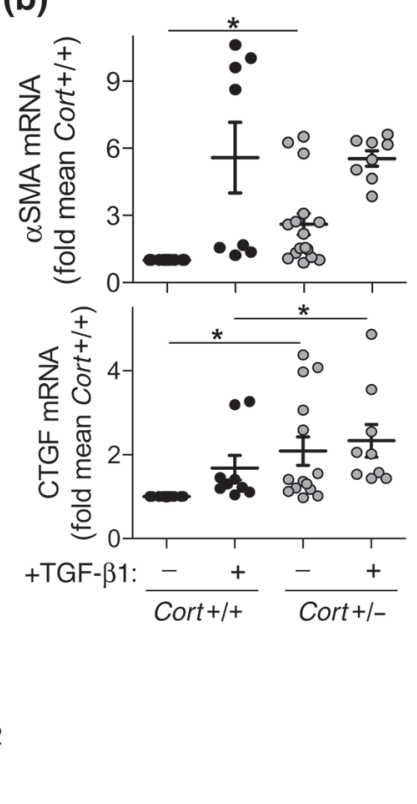

(c)
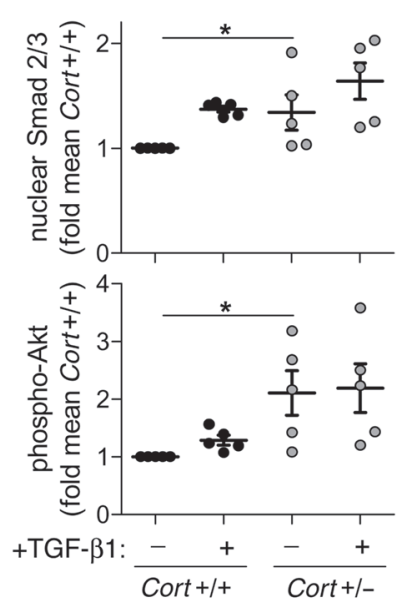
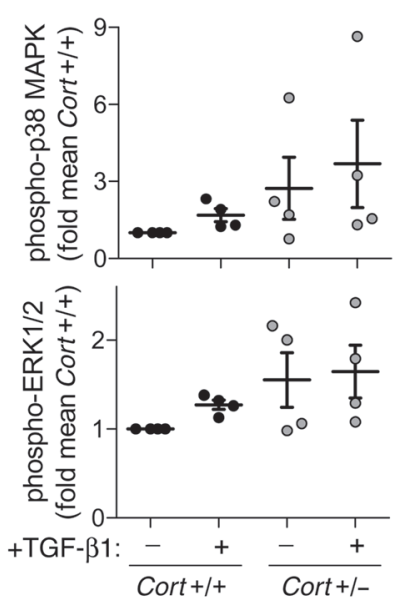

CTGF

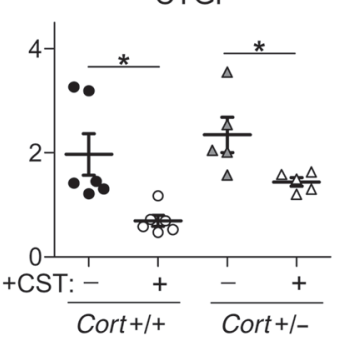

Col1a2

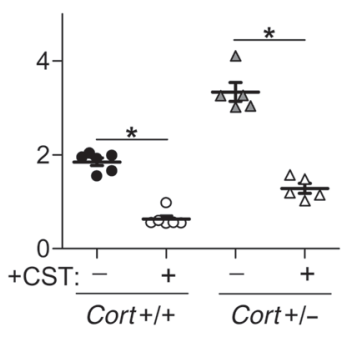

Fibronectin

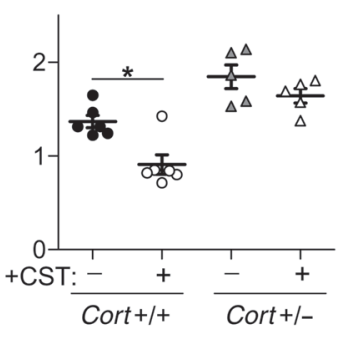

FIGURE 6 Cortistatin (CST)-deficient fibroblasts show exacerbated profibrotic responses. (a) Gene expression of cortistatin by unstimulated and TGF- $\beta 1$-activated mouse primary lung fibroblasts ( $n=3$ cultures) and by lungs isolated from naïve or bleomycin (Bleo)-treated mice ( $n=5$ mice per group). (b-d) Primary lung fibroblasts were isolated from wild-type (Cort $+/+$ ) and partially deficient (Cort $+/-)$ mice for cortistatin were cultured in the absence $(-)$ or presence $(+)$ of TGF- $\beta 1\left(10 \mathrm{ng} \cdot \mathrm{ml}^{-1}\right)$ stimulation. (b) $\alpha \mathrm{SMA}$ and CTGF gene expression was determined after 24-h culture (13 unstimulated cultures and nine stimulated cultures). (c) Nuclear translocation of activated Smad2/3 was determined by immunofluorescence analysis and the levels of activated phosphorylated Akt, p38 MAPK and ERK1/2 were analysed by western blot after $1 \mathrm{~h}$ of culture ( $n=4-5$ independent experiments, in triplicates). See Figure S1 for representative immunofluorescence images and western blots.

(d) Fibroblast migration activity was measured at different time points using an in vitro wound healing assay ( $n=6$ independent cultures). (e) Fibroblasts isolated from Cort $+/+$ and Cort $+/$ - lungs were stimulated with TGF- $\beta 1$ in the absence (-) or presence (+) of cortistatin, and the gene expression of $\alpha \mathrm{SMA}, \mathrm{CTGF}$, collagen l $\alpha 2$ (Col1a2) and fibronectin was determined after 24 -h culture ( $n=5-6$ independent cultures). Results are the mean \pm SEM with dots representing individual values of independent experiments. Data in (b), (c) and (e) are expressed as fold change relative to the mean of unstimulated Cort $+/+$ fibroblasts. ${ }^{*} P<0.05$

Thus, the activation and subsequent nuclear translocation of Smad2/3 was significantly increased in Cort+/- fibroblasts (Figures 6c and S1A). Moreover, the basal levels of activated phosphorylated forms of various protein kinases, including Akt, p38 MAPK and ERK1/2, were markedly increased in cortistatin-deficient fibroblasts, showing similar or even higher activation levels than those showed by TGF- $\beta 1$-activated Cort $+/+$ fibroblasts (Figures $6 c$ and S1B). Furthermore, in comparison with wild-type fibroblasts, cortistatin-deficient pulmonary fibroblasts showed accelerated and increased migratory responses in a wound healing assay (Figure 6d). However, lack of cortistatin did affect neither fibroblast growth nor viability (Figure S2). We finally assessed its antifibrotic effect by adding cortistatin to cultures of TGF- $\beta 1$-activated Cort $+/+$ and Cort $+/$ - fibroblasts. As expected, treatment with cortistatin significantly reduced the expression of profibrotic markers and extracellular matrix components, including aSMA, CTGF, Col1a2 and fibronectin, in activated lung fibroblasts (Figure 6e). Therefore, these findings indicate that cortistatin could act as an endogenous break of activation, migration and differentiation of fibroblasts.

\subsection{Treatment with cortistatin ameliorates bleomycin-induced pulmonary inflammation and fibrosis}

Our previous results indicate that cortistatin has a critical role in the regulation of pulmonary inflammation and fibrosis and that administration of cortistatin is a potential strategy for the prevention and 
treatment of lung injury-induced fibrosis. The systemic injection of cortistatin at the early stage significantly prevented the profound body weight loss, high mortality and severe pulmonary fibrosis that were induced by the administration of high-dose bleomycin (Figure 7a). These protective effects correlated with inhibition of pulmonary inflammation, injury and vascular leak (Figure 7a). Importantly, cortistatin also therapeutically attenuated bleomycin-induced mortality and the severity of pulmonary fibrosis at the later stages following bleomycin instillation (Figure 7b). Indeed, treatment of animals with cortistatin beginning 5 days after bleomycin challenge, once that pulmonary inflammation was fully established, significantly improved fibrosis score, reduced collagen deposition and decreased the presence of $\alpha \mathrm{SMA}$-expressing myofibroblasts in lung (Figure 7b). We found similar therapeutic efficiencies using both systemic (i.p.) and local (i.n., at 20-fold lower doses) routes of administration (Figure 7b). Noteworthy from a therapeutic point of view is the fact that cortistatin treatment was able to reverse the susceptibility to suffer severe pulmonary fibrosis in mice that had a partial deficiency in cortistatin after their exposition to low doses of bleomycin (Figure 8). These results suggest that cortistatin-based therapies could impair pulmonary inflammation and attenuate the established pulmonary fibrosis.

\section{5 | Involvement of somatostatin and ghrelin receptors in the therapeutic effect of cortistatin in pulmonary inflammation and fibrosis}

We finally investigated the receptors through which cortistatin could exert its anti-inflammatory and antifibrotic activities in vivo. Previous evidence demonstrates the capacity of cortistatin to bind, between others, to SST receptors and ghrelin receptor (Gonzalez-Rey \& Delgado, 2007), supports that both receptors play major roles in the immunomodulatory effect of cortistatin in several organs (GonzalezRey \& Delgado, 2008) and indicates that signalling through SST receptors and ghrelin receptor exerts antifibrotic actions other tissues (Borie et al., 2008; Egger et al., 2014; Tug et al., 2013). Local administration by intranasal infusion of either a potent $\mathrm{SST}_{1-5}$ antagonist or a specific ghrelin receptor antagonist partially blocked the protective effects observed for cortistatin in Cort+/- mice subjected to LPS-induced ALI (Figure 9a) and bleomycin-induced pulmonary fibrosis (Figure 9b). These results suggest that cortistatin exerts its anti-inflammatory and antifibrotic actions in the lungs by signalling through both SST receptors and ghrelin receptor.

\section{4 | DISCUSSION}

Inflammation and wound healing are two physiological processes aimed at restoring normal tissue structure and function after an insult or injury. However, they can be more damaging than the insult itself if uncontrolled, excessive or prolonged. In the lung, a dysregulated inflammation causes excessive leukocyte accumulation and increased permeability of endothelial and alveolar epithelial barriers. A wound healing response that has gone out of control after lung injury causes pulmonary fibrosis, which is characterized by progressive loss of alveolar structure, disruption of the epithelial-endothelial barrier, activation of fibroblasts and their differentiation to myofibroblasts, excessive deposition of extracellular matrix and tissue remodelling. Far of restoring host pulmonary homeostasis, aberrant inflammatory and fibrotic responses, in some cases being part of the same cascade, contribute to the pathogenesis of severe lung disorders, such as ALI/ARDS and IPF. A precise balance of inflammatory/fibrogenic versus immunomodulatory/antifibrotic factors must exist to tune adequately these responses. The identification of the factors that limit or reverse both processes is critical for understanding the pathophysiology and identifying new therapeutic targets for these disorders. In this study, by using two well-characterized experimental models of ARDS and pulmonary fibrosis, we point out to cortistatin as an endogenous protective factor. We found that a deficiency in cortistatin predisposes for developing exacerbated inflammatory and fibrotic responses in injured lungs after exposition to bacterial endotoxins or chemotherapeutic drugs, even at low doses, and to subsequently suffer more severe disease progression and increased mortality. Moreover, our data show that a treatment with cortistatin is able to mitigate these pathological processes.

We envision the involvement of various non-excluding and complementary cellular and molecular mechanisms that could explain the protective effect of cortistatin in pulmonary inflammation and fibrosis (Figure 10). First, previous reports demonstrated the antiinflammatory activity of cortistatin on macrophages and described its protective effect in murine models of sepsis and endotoxemia, acting mainly by regulating a wide range of inflammatory mediators (Gonzalez-Rey, Chorny, Robledo, \& Delgado, 2006; Gonzalez-Rey, Varela, Sheibanie, et al., 2006). Here, we have confirmed that in the lung cortistatin down-regulates the production of various inflammatory cytokines and chemokines by activated BALF macrophages. Further, and importantly, we found that infiltrating pulmonary macrophages, that are deficient in cortistatin produced excessive levels of cytokines that are responsible for the pathophysiology of ALI/ARDS. This effect could be initiated in an autocrine/paracrine manner, as macrophages express both cortistatin (Dalm et al., 2003; Gonzalez-Rey, Chorny, Robledo, \& Delgado, 2006; Gonzalez-Rey, Varela, Sheibanie, et al., 2006; Markovics et al., 2012), as well as both somatostatin and ghrelin receptors, which are involved in the antiinflammatory activity of cortistatin (Gonzalez-Rey \& Delgado, 2007). Indeed, we found that blockade of any of these receptors, mainly the ghrelin receptor, impaired the protective action of cortistatin in ALI. Moreover, its action on macrophages could orchestrate the infiltration of other leukocytes (i.e. neutrophils) involved in pulmonary inflammation and fibrosis. Furthermore, the immunomodulatory activity of cortistatin on lymphocytes is widely recognized besides having a potent suppressive effect on Th1 cell-mediated inflammatory responses. Further, we have previously found that a major mechanism involved in the generation of immune tolerance by cortistatin is the induction of regulatory T cells (Gonzalez-Rey, Chorny, \& Delgado, 2007), 


$$
\text { (a) Bleo } 3.2 \text { U.kg-1, i.t. }
$$

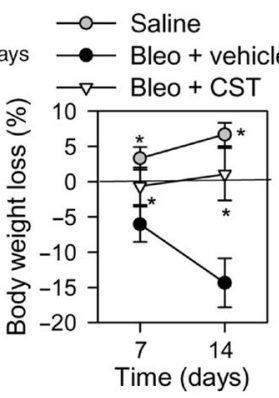

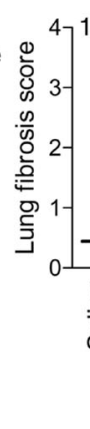

$\rightarrow-$ Saline

$\rightarrow$ Bleo + vehicle

$\rightarrow-$ Bleo + CST

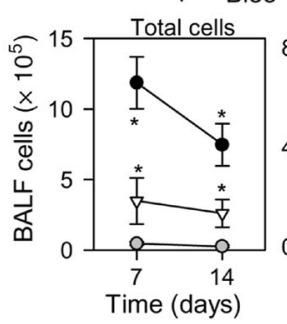

(b)

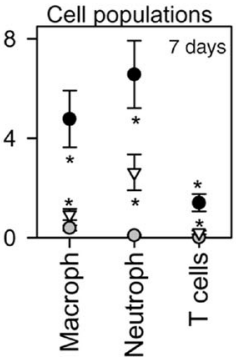

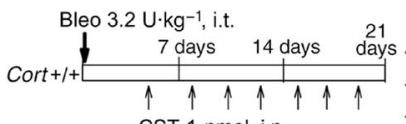
CST 1 nmol, i.p. Vehicle i.n./i.p.

$\longrightarrow$ Bleo + vehicle $(n=35)$

$\rightarrow-$ Bleo + CST i.n. $(n=16)$

$\rightarrow-$ Bleo + CST i.p. $(n=16)$
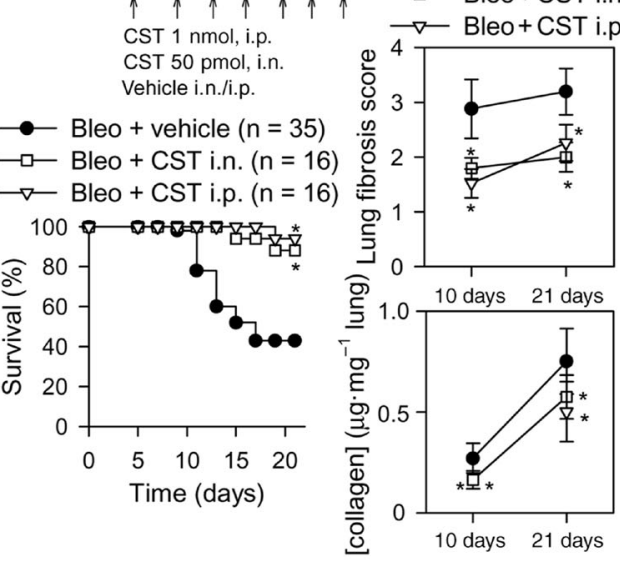

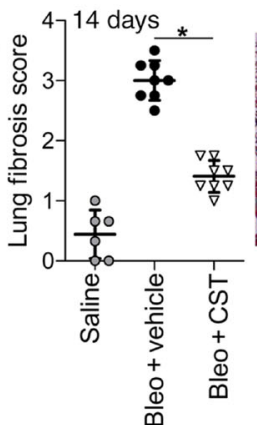

$\longrightarrow$ - Saline
$\multimap \quad \longrightarrow$ Bleo + vehicle
$\multimap-$ Bleo + CST

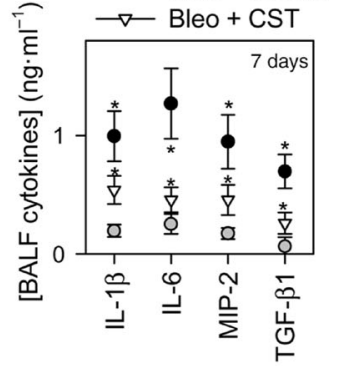

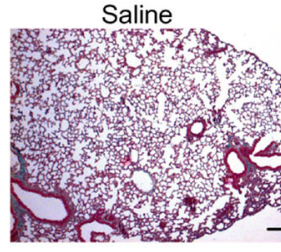

Bleo + vehicle

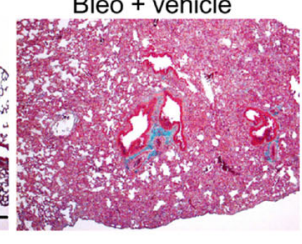

Bleo+CST
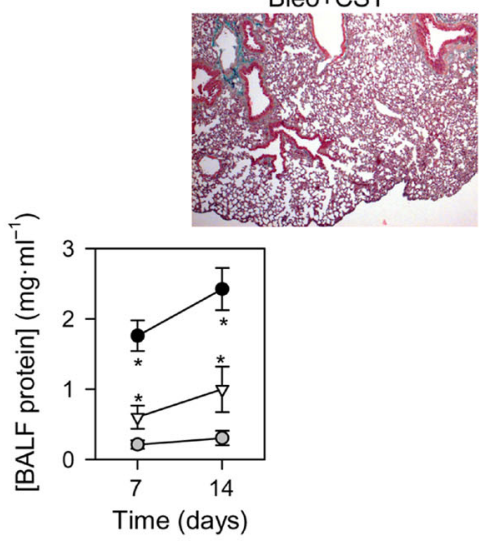
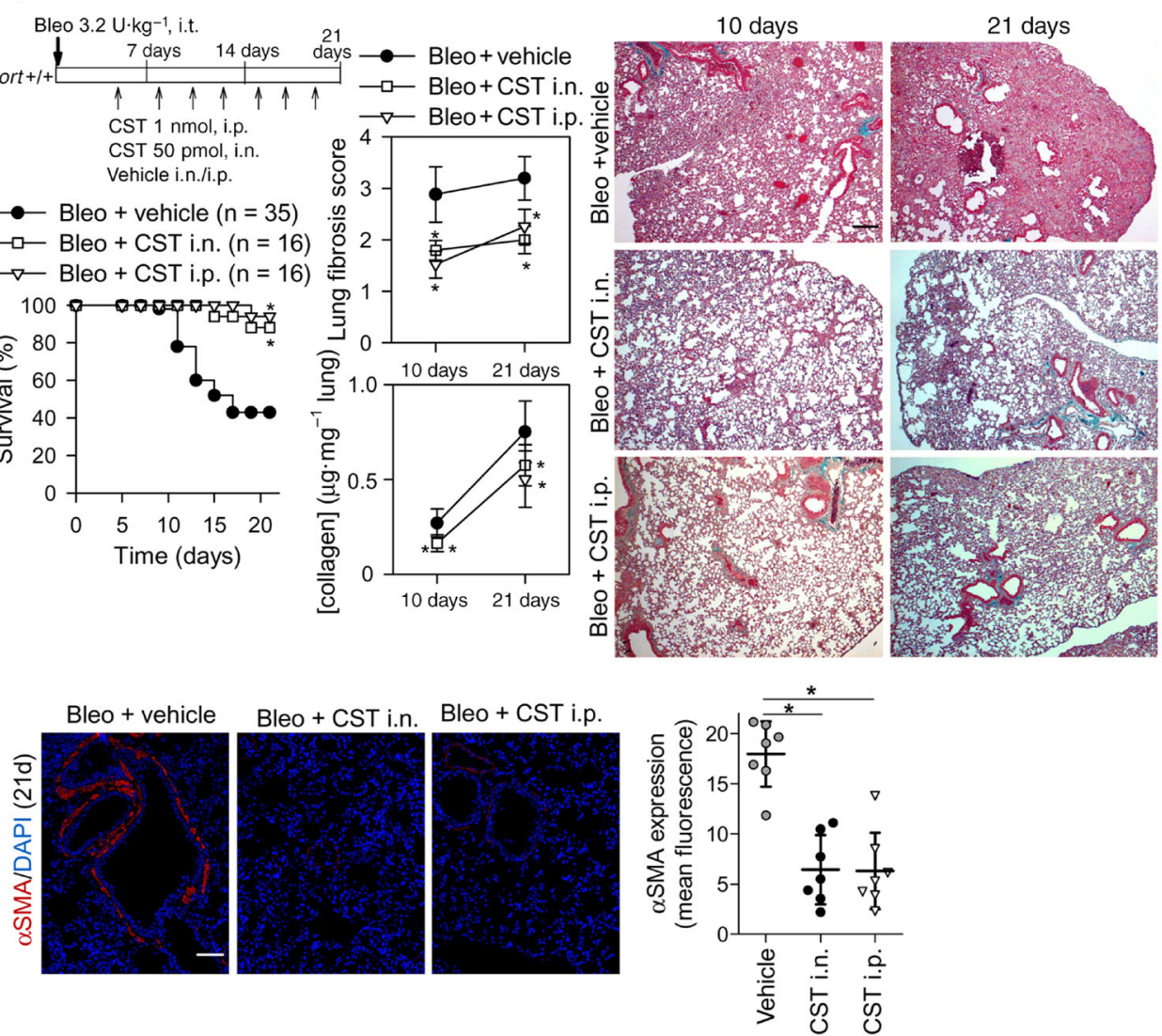

FIGURE 7 Treatment with cortistatin (CST) reduces mortality and disease severity of experimental lung fibrosis. Mice with bleomycin (Bleo)induced severe pulmonary fibrosis were treated with vehicle or with cortistatin following an early protective regime (a) or a delayed therapeutic regime (b) as indicated in the two schemes. Mice injected intratracheally with saline instead of bleomycin were used as basal controls $(n=6)$. Mortality, body weight loss (eight mice per group) and histopathological signs of lung fibrosis (eight mice per group in a and 7-13 mice per group in b) were determined at the indicated time points. Pulmonary leukocyte infiltration and the levels of inflammatory cytokines and oedema (protein levels) were assayed in bronchoalveolar lavage fluids (BALFs; six mice per group). Fibrogenic markers including the content of collagen (10 mice per group) and the presence of $\alpha$ SMA-positive myofibroblasts (expressed as fluorescence mean, seven mice per group) were determined in lungs isolated at the indicated time points. Scale bars: $150 \mu \mathrm{m}$. Results are the mean \pm SD with dots representing individual values of biologically independent animals. ${ }^{*} P<0.05$ versus Bleo + vehicle-treated mice 

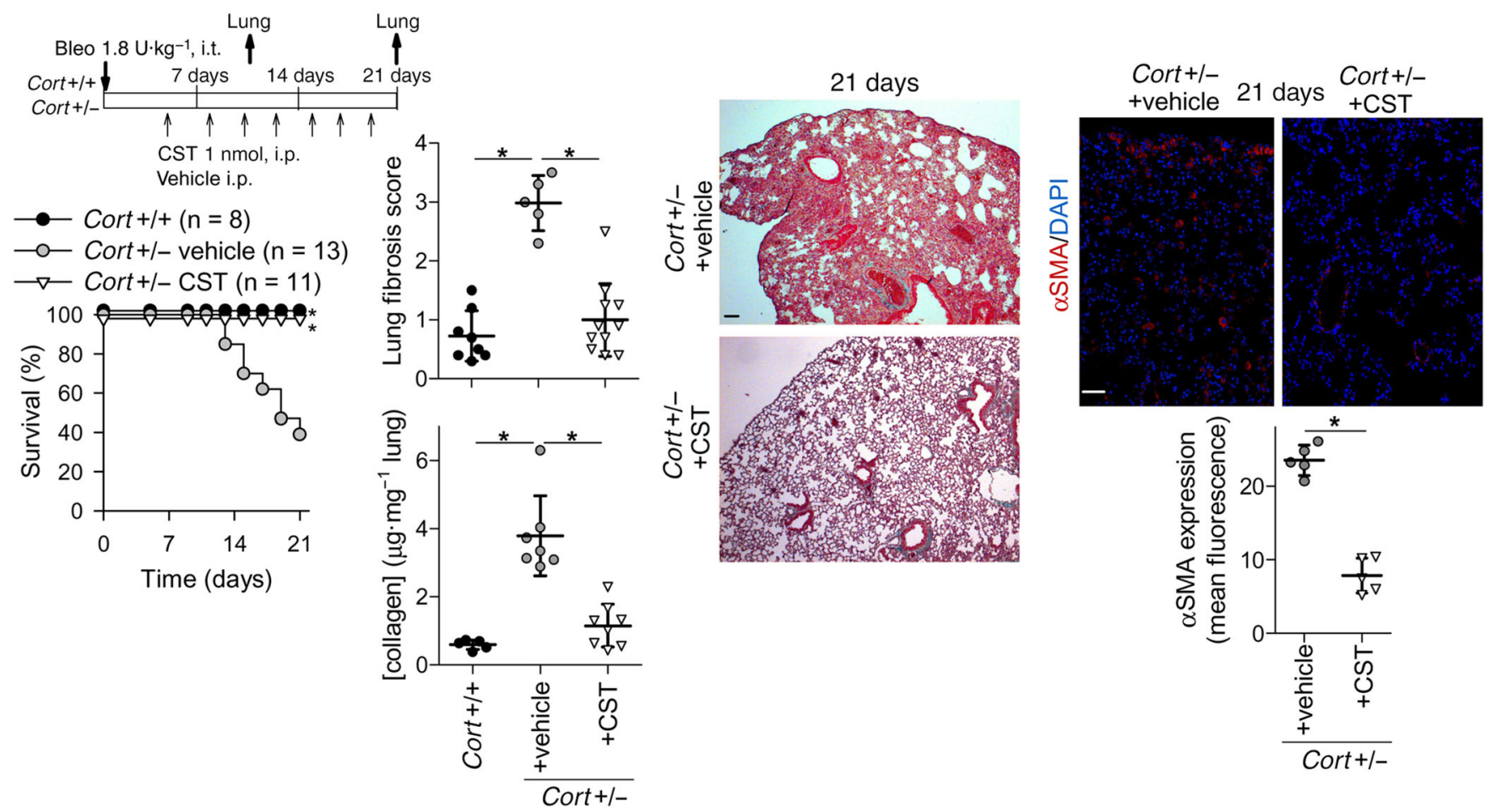

FIGURE 8 Exogenous administration of cortistatin (CST) reversed the exacerbated fibrogenic phenotype observed in cortistatin-deficient mice. Lung fibrosis was induced in partially deficient mice (Cort+/-) for cortistatin and treated with vehicle or cortistatin as indicated in the scheme. Bleomycin (Bleo)-challenged Cort+/+ mice were used as controls of reference. Mortality, histopathological signs of fibrosis (5-11 mice per group), pulmonary collagen content (7-8 mice per group) and the presence of $\alpha$ SMA-positive myofibroblasts (five mice per group) were determined in lungs isolated at the indicated time points. Scale bars: $100 \mu \mathrm{m}$. Results are the mean \pm SD with dots representing individual values of biologically independent animals. ${ }^{*} P<0.05$

a T-cell subpopulation that is involved in amelioration of ALI/ARDS and pulmonary fibrosis (D'Alessio et al., 2009). These findings open the possibility that, by regulating the inflammatory/immune response in the lung, cortistatin could impair an initial step in the profibrotic cascade and thus mitigate subsequent progression to pulmonary fibrosis. Although the immunomodulatory action of cortistatin could contribute to its antifibrotic role, evidence suggests a direct and additional action of cortistatin on the fibrogenic effectors in the lung. We found that pulmonary fibroblasts isolated from cortistatindeficient mice showed overactivated TGF- $\beta 1$-signalling pathways, including Smad2/3, Akt and MAPKs (p38 and ERK1/2), that drive the expression of genes (for example, collagen, CTGF and $\alpha \mathrm{SMA}$ ) that are involved in pathological fibrosis (Wynn, 2011). Again, this effect could be mediated in a paracrine fashion, because fibroblasts express both cortistatin and its receptors (Borie et al., 2008; Egger et al., 2014; this study; Tug et al., 2013). In this respect, we observed that exogenously added cortistatin inhibited directly the expression of several mediators and markers of fibrosis by TGF- $\beta 1$-activated fibroblasts. In agreement, various studies have reported the effect of cortistatin in MAPKs and Akt in other cell types (Duran-Prado et al., 2013; Morell et al., 2014) and other somatostatin receptor agonists regulate the activation of fibroblasts (Borie et al., 2008; Wang et al., 2013). Moreover, by using selective antagonists, we provide evidence that somatostatin and ghrelin receptors play major roles in the antifibrotic effects of cortistatin in the lung. The potential capacity of cortistatin to synergistically signal through both classes of receptors could suppose an advantage versus somatostatin and ghrelin in regulating fibrotic responses. Interestingly, we observed a negative correlation between expression of cortistatin and the activation of pulmonary fibroblasts, confirming that cortistatin acts as an endogenous break that needs to be released for allowing fibroblast activation. Finally, the fact that treatment with cortistatin efficiently reduced fibrotic responses in bleomycin-challenged mice, when initiated once the inflammatory response was fully established in the lung, also supports the capacity of cortistatin to directly limit the fibrogenic response.

Our findings have multiple clinical implications from both therapeutic and from a diagnostic point of view. First, we demonstrated that cortistatin-based therapies emerge as attractive alternatives for treatment of pulmonary disorders which involve hyperactivated inflammatory and fibrotic responses, such as in ALI/ARDS and IPF. Despite the enormous progression made in the identification of the pathogenic mechanisms involved in the initiation and progression of these diseases, they are an enduring problem in respiratory and critical medicine that remains therapeutically unresolved, as they remain a major cause of morbidity and mortality worldwide (Matthay et al., 2017). This urgent need has acquired a global dimension lately during the pandemic COVID-19, with the association of severe ARDS 

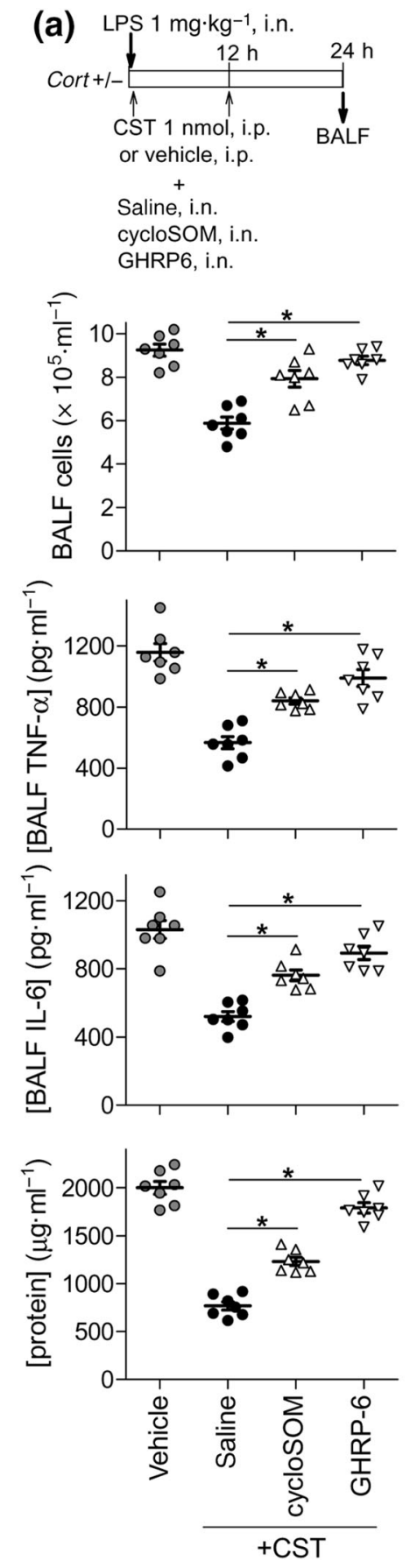

(b)
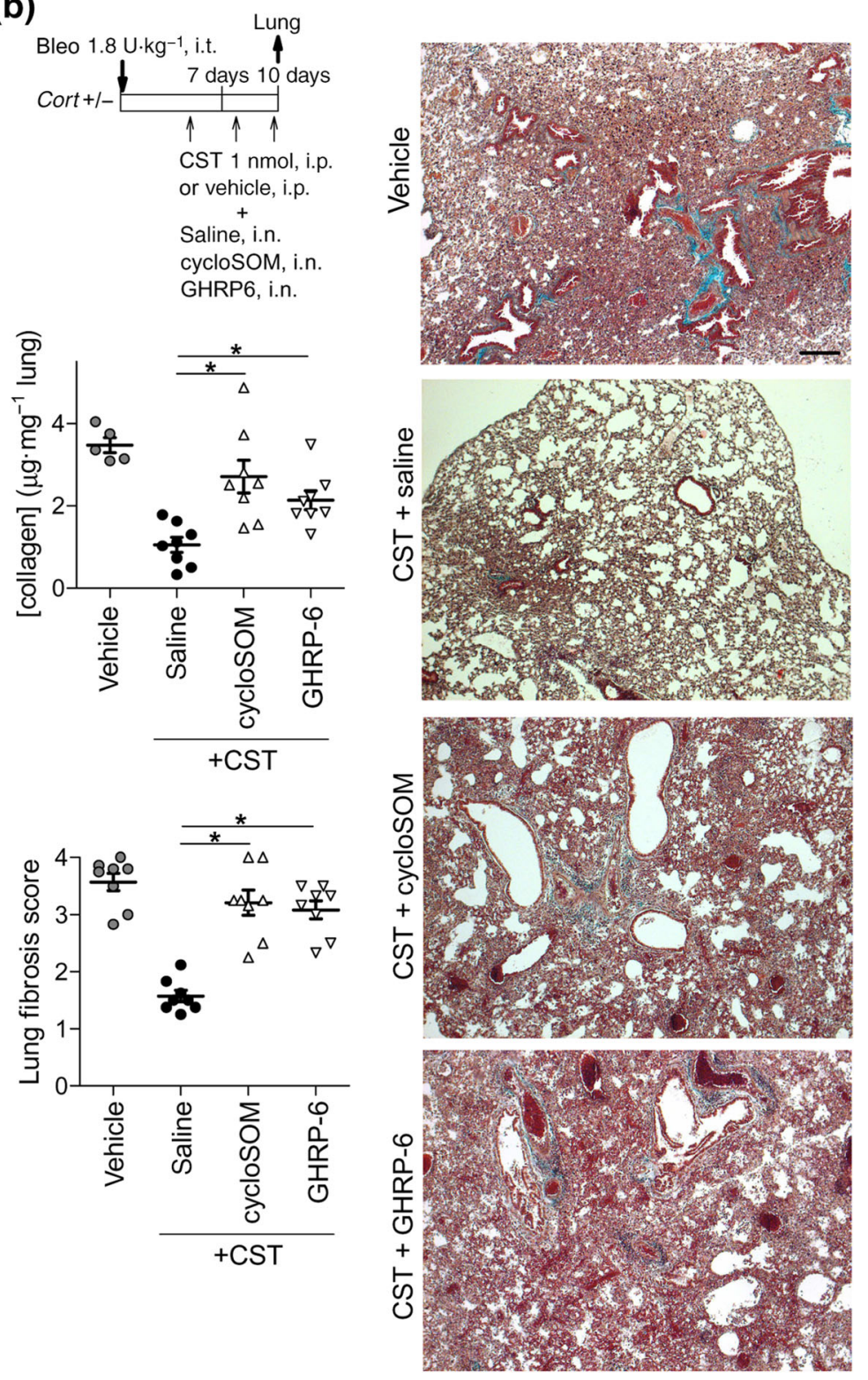

FIGURE 9 Involvement of somatostatin receptors and ghrelin receptor in the therapeutic effect of cortistatin (CST) in acute lung injury (ALI) and pulmonary fibrosis. (a) ALI was induced in partially deficient mice for cortistatin (Cort+/-) by intranasal injection of LPS and then treated intraperitoneally with vehicle or cortistatin. Saline, a SST $1-5$ antagonist (cyclosomatostatin, cycloSOM), or a ghrelin receptor (GHSR) antagonist ([D-Lys $\left.\left.{ }^{3}\right]-G H R P-6\right)$ was injected intranasally (i.n.) 30 min before cortistatin injection as indicated in the scheme. Leukocyte infiltration, and protein and cytokine contents were determined in bronchoalveolar lavage fluids (BALFs) isolated $24 \mathrm{~h}$ after LPS-induced ALI ( $n=7$ mice per group). (b) Lung fibrosis was induced in Cort $+/-$ mice with bleomycin and then treated with vehicle or cortistatin as indicated in the scheme. Saline, cycloSOM or [D-Lys ${ }^{3}$ ]-GHRP-6 was injected i.n. 30 min before cortistatin injection. Histopathological signs of fibrosis and the contents of collagen were determined in lungs collected 10 days after bleomycin challenge (5-8 mice per group). Results are the mean \pm SD with dots representing individual values of biologically independent animals. ${ }^{*} P<0.05$

and pulmonary fibrosis which has a poor prognosis in SARSCoV-2-infected patients (Mehta et al., 2020). Due to the redundancy and complexity of the cytokine and fibrogenic network, the multitargeted action of cortistatin as an immunomodulatory agent on a plethora of mediators of the cytokine storm offers obvious advantages versus other therapies based on neutralization of a single 
(a) Healthy alveolus

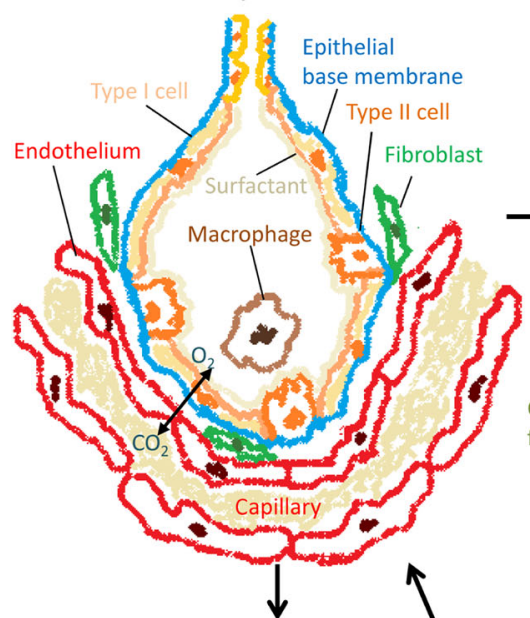

(c) ARDS and severe fibrosis in CST-deficient mice

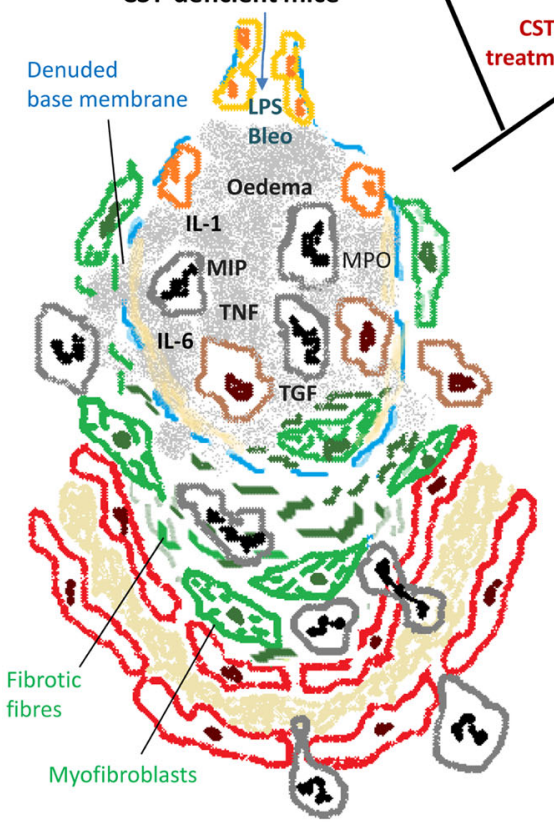

(b) ALI and fibrosis

in Cort+/+ mice 
molecule (i.e. monoclonal antibodies). Moreover, cortistatin-based therapies could limit the start of late-onset pulmonary fibrosis in patients with ARDS or COVID-19 in post-infection stages. It is important to mention that cortistatin has a favourable safety profile in humans and has demonstrated clinical efficacy in patients with Cushing's disease (Giordano et al., 2007). Furthermore, the interest of the pharmaceutical companies in developing cortistatin-based analogues with improved half-life in serum has increased lately and a recent report demonstrated their efficiency in inflammatory conditions (Rol et al., 2021). We have recently witnessed an example of repositioning of a therapy based on another immunomodulatory and antifibrotic neuropeptide, vasoactive intestinal peptide (VIP) or aviptadil (Chorny \& Delgado, 2008; Prasse et al., 2010), for the treatment of ARDS in patients with severe COVID-19 (Scavone et al., 2020; clinical trial: NCT04311697).

Second, the fact that a simple partial deficiency in cortistatin could predispose patients for developing exacerbated inflammatory and fibrotic responses and could be used to anticipate the diagnostically the developmen of more severe forms of pulmonary disorders. In this sense, this study opens the possibility of initiating further clinical research that could corroborate plasma cortistatin level as a biomarker of protection or prognosis in patients with ARDS or IPF. If this is the case, our results also suggest that a treatment based on cortistatin injection would easily correct this deficiency and improve disease progression. Although the endogenous and environmental factors that could influence the body levels of cortistatin are mostly unknown, one could anticipate that these levels will change during our life under different circumstances and scenarios, and thus our susceptibility to suffer certain disorders. In any case, a percentage of the human population is heterozygous for cortistatin from birth, because cortistatin gene is located at chromosome $1 p 36.22$ and monosomy of $1 \mathrm{p} 36$ is the most common subtelomeric terminal deletion syndrome (Jordan et al., 2015). Besides a spectrum of neurological and sensorial defects, these individuals develop cardiac fibrosis and cardiomyopathy, however no studies have described increased incidence of pulmonary disorders, despite their short life expectancy.

Finally, bleomycin is a chemotherapeutic drug used for treating many types of cancer. Unfortunately, a proportion of bleomycintreated patients develop severe side effects that are associated to appearance of pulmonary and skin fibrosis that mostly cause treatment to be withdrawn. Understanding that a deficiency in a factor like cortistatin could predispose patients to such adverse effects could help selection of the correct chemotherapy or try to correct the adverse effects by cortistatin-based treatments.

In summary, this study provides new insights into the function of cortistatin in pulmonary inflammation and demonstrates a novel role of this neuropeptide in fibrosis, which could be extrapolated beyond lung tissue. Overall, we demonstrate that deficiency in cortistatin could be considered a potential biomarker of susceptibility to suffer severe forms of pulmonary disorders including ARDS, IPF or pneumonia and provide a powerful rationale for the assessment of the efficacy of cortistatin or its stable analogues as therapeutic approaches to the treatment of diseases that are still unsolved from a clinical point of view. However, because the effects observed are based on preclinical mouse models of ALI/ARDS in the absence of viral or bacterial infection, and many pulmonary fibrotic disorders are of idiopathic nature, extrapolations to clinical practice have to be made with caution.

\section{ACKNOWLEDGEMENTS}

We thank to Dr Luis de Lecea (Stanford University, CA, USA) for providing the Cort-/- mice to establish initially the colony of animals used in this study. This study was mainly supported by the Spanish Ministry of Science and Innovation (Ministerio de Ciencia e Innovación [MICINN], Grant SAF2015-67787-R). R.B. was a recipient of FPI fellowship from the Spanish Ministry of Science and Innovation, and M.G.-F. was a recipient of FPU fellowship from the Spanish Ministry of Universities. V.F.-P. was a recipient of postdoctoral fellowship from Fundação de Amparo à Pesquisa do Estado de São Paulo-FAPESP (12/21767-5).

\section{AUTHOR CONTRIBUTIONS}

M.B. and J.C.-S. conducted most of the experiments and analysed the data. M.C. and G.R. carried out the histological processing and ELISA determinations. V.F.-P. conducted the part of in vivo experimental models. R.B., M.G.-F. and F.O. performed the histopathological studies. M.D. conceived and designed the study, conducted the in vivo experimental models, analysed the data and wrote the manuscript. All the authors edited the manuscript.

\section{CONFLICT OF INTEREST}

The authors declare no conflicts of interest.

\section{DECLARATION OF TRANSPARENCY AND SCIENTIFIC RIGOUR}

This Declaration acknowledges that this paper adheres to the principles for transparent reporting and scientific rigour of preclinical research as stated in the British Journal of Pharmacology guidelines for Design \& Analysis, Immunoblotting and Immunochemistry and Animal Experimentation and as recommended by funding agencies, publishers and other organizations engaged with supporting research.

\section{DATA AVAILABILITY STATEMENT}

The data that support the findings of this study are available from the corresponding author upon reasonable request.

\section{ORCID}

Mario Delgado (D) https://orcid.org/0000-0003-1893-5982

\section{REFERENCES}

Alexander, S. P. H., Christopoulos, A., Davenport, A. P., Kelly, E., Mathie, A., Peters, J. A., Veale, E. L., Armstrong, J. F., Faccenda, E., Harding, S. D., Pawson, A. J., Sharman, J. L., Southan, C., Davies, J. A., \& CGTP Collaborators. (2019). The Concise Guide to PHARMACOLOGY 2019/20: G protein-coupled receptors. British Journal of Pharmacology, 176, S21-S141. 
Alexander, S. P. H., Roberts, R. E., Broughton, B. R. S., Sobey, C. G. George, C. H., Stanford, S. C., Cirino, G., Docherty, J. R., Giembycz, M. A., Hoyer, D., Insel, P. A., Izzo, A. A., Ji, Y., MacEwan, D. J., Mangum, J., Wonnacott, S., \& Ahluwalia, A. (2018). Goals and practicalities of immunoblotting and immunohistochemistry: A guide for submission to the British Journal of Pharmacology. British Journal of Pharmacology, 175, 407-411. https://doi.org/10.1111/bph. 14112

Ashcroft, T., Simpson, J. M., \& Timbrell, V. (1988). Simple method of estimating severity of pulmonary fibrosis on a numerical scale. Journal of Clinical Pathology, 41, 467-470. https://doi.org/10.1136/jcp.41.4.467

Borie, R., Fabre, A., Prost, F., Marchal-Somme, J., Lebtahi, R., MarchandAdam, S., Aubier, M., Soler, P., \& Crestani, B. (2008). Activation of somatostatin receptors attenuates pulmonary fibrosis. Thorax, 63, 251-258. https://doi.org/10.1136/thx.2007.078006

Chorny, A., \& Delgado, M. (2008). Neuropeptides rescue mice from lethal sepsis by downregulating secretion of the late-acting inflammatory mediator high mobility group box 1 . The American Journal of Pathology, 172, 1297-1307. https://doi.org/10.2353/ajpath.2008.070969

Cordoba-Chacon, J., Gahete, M. D., Pozo-Salas, A. I., MartínezFuentes, A. J., de Lecea, L., Gracia-Navarro, F., Kineman, R. D., Castaño, J. P., \& Luque, R. M. (2011). Cortistatin is not a somatostatin analogue but stimulates prolactin release and inhibits $\mathrm{GH}$ and ACTH in a gender-dependent fashion: Potential role of ghrelin. Endocrinology, 152, 4800-4812. https://doi.org/10.1210/en.2011-1542

Curtis, M. J., Alexander, S., Cirino, G., Docherty, J. R., George, C. H., Giembycz, M. A., Hoyer, D., Insel, P. A., Izzo, A. A., Ji, Y., MacEwan, D. J., Sobey, C. G., Stanford, S. C., Teixeira, M. M., Wonnacott, S., \& Ahluwalia, A. (2018). Experimental design and analysis and their reporting II: Updated and simplified guidance for authors and peer reviewers. British Journal of Pharmacology, 175, 987-993. https://doi.org/10.1111/bph.14153

D'Alessio, F. R., Tsushima, K., Aggarwal, N. R., West, E. E., Willett, M. H., Britos, M. F., Pipeling, M. R., Brower, R. G., Tuder, R. M., McDyer, J. F., \& King, L. S. (2009). CD4 ${ }^{+}$CD25 ${ }^{+}$Foxp3 ${ }^{+}$Tregs resolve experimental lung injury in mice and are present in humans with acute lung injury. The Journal of Clinical Investigation, 119, 2898-2913. https://doi.org/ $10.1172 / \mathrm{JCl} 36498$

Dalm, V. A., van Hagen, P. M., van Koetsveld, P. M., Achilefu, S., Houtsmuller, A. B., Pols, D. H., van der Lely, A. J., Lamberts, S. W., \& Hofland, L. J. (2003). Expression of somatostatin, cortistatin, and somatostatin receptors in human monocytes, macrophages, and dendritic cells. American Journal of Physiology. Endocrinology and Metabolism, 285, E344-E353. https://doi.org/10.1152/ajpendo. 00048.2003

Delgado-Maroto, V., Falo, C. P., Forte-Lago, I., Adan, N., Morell, M., Maganto-Garcia, E., Robledo, G., O'Valle, F., Lichtman, A. H., Gonzalez-Rey, E., \& Delgado, M. (2017). The neuropeptide cortistatin attenuates experimental autoimmune myocarditis via inhibition of cardiomyogenic $\mathrm{T}$ cell-driven inflammatory responses. British Journal of Pharmacology, 174, 267-280. https://doi.org/10. 1111/bph.13682

Duran-Prado, M., Morell, M., Delgado-Maroto, V., Castaño, J. P., AneirosFernandez, J., de Lecea, L., Culler, M. D., Hernandez-Cortes, P., O'Valle, F., \& Delgado, M. (2013). Cortistatin inhibits migration and proliferation of human vascular smooth muscle cells and decreases neointimal formation on carotid artery ligation. Circulation Research 112, 1444-1455. https://doi.org/10.1161/CIRCRESAHA.112.300695

Egger, C., Gérard, C., Vidotto, N., Accart, N., Cannet, C., Dunbar, A. Tigani, B., Piaia, A., Jarai, G., Jarman, E., Schmid, H. A., \& Beckmann, N. (2014). Lung volume quantified by MRI reflects extracellular-matrix deposition and altered pulmonary function in bleomycin models of fibrosis: Effects of SOM230. American Journal of Physiology. Lung Cellular and Molecular Physiology, 306, L1064-L1077. https://doi.org/10. 1152/ajplung.00027.2014
George, P. M., Wells, A. U., \& Jenkins, R. G. (2020). Pulmonary fibrosis and COVID-19: The potential role for antifibrotic therapy. The Lancet Respiratory Medicine, 8, 807-815. https://doi.org/10.1016/S22132600(20)30225-3

Giordano, R., Picu, A., Bonelli, L., Broglio, F., Prodam, F., Grottoli, S., Muccioli, G., Ghigo, E., \& Arvat, E. (2007). The activation of somatostatinergic receptors by either somatostatin-14 or cortistatin17 often inhibits ACTH hypersecretion in patients with Cushing's disease. European Journal of Endocrinology, 157, 393-398. https://doi. org/10.1530/EJE-07-0147

Gonzalez-Rey, E., Chorny, A., Del Moral, R. G., Varela, N., \& Delgado, M. (2007). Therapeutic effect of cortistatin on experimental arthritis by downregulating inflammatory and Th1 responses. Annals of the Rheumatic Diseases, 66, 582-588. https://doi.org/10.1136/ard.2006. 062703

Gonzalez-Rey, E., Chorny, A., \& Delgado, M. (2007). Regulation of immune tolerance by anti-inflammatory neuropeptides. Nature Reviews. Immunology, 7, 52-63. https://doi.org/10.1038/nri1984

Gonzalez-Rey, E., Chorny, A., Robledo, G., \& Delgado, M. (2006). Cortistatin, a new antiinflammatory peptide with therapeutic effect on lethal endotoxemia. The Journal of Experimental Medicine, 203, 563-571. https://doi.org/10.1084/jem.20052017

Gonzalez-Rey, E., Chorny, A., Varela, N., Robledo, G., \& Delgado, M. (2006). Urocortin and adrenomedullin prevent lethal endotoxemia by down-regulating the inflammatory response. The American Journal of Pathology, 168, 1921-1930. https://doi.org/10.2353/ajpath.2006. 051104

Gonzalez-Rey, E., \& Delgado, M. (2007). Anti-inflammatory neuropeptide receptors: New therapeutic targets for immune disorders? Trends in Pharmacological Sciences, 28, 482-491. https://doi.org/10.1016/j.tips. 2007.07.001

Gonzalez-Rey, E., \& Delgado, M. (2008). Emergence of cortistatin as a new immunomodulatory factor with therapeutic potential in immune disorders. Molecular and Cellular Endocrinology, 286, 135-140. https://doi. org/10.1016/j.mce.2007.08.001

Gonzalez-Rey, E., Varela, N., Sheibanie, A. F., Chorny, A., Ganea, D., \& Delgado, M. (2006). Cortistatin, an antiinflammatory peptide with therapeutic action in inflammatory bowel disease. Proceedings of the National Academy of Sciences of the United States of America, 103, 4228-4233. https://doi.org/10.1073/pnas.0508997103

Jordan, V. K., Zaveri, H. P., \& Scott, D. A. (2015). 1p36 deletion syndrome: An update. The Application of Clinical Genetics, 8, 189-200. https:// doi.org/10.2147/TACG.S65698

Kolb, P., Upagupta, C., Vierhout, M., Ayaub, E., Bellaye, P. S., Gauldie, J., Shimbori, C., Inman, M., Ask, K., \& Kolb, M. R. J. (2020). The importance of interventional timing in the bleomycin model of pulmonary fibrosis. The European Respiratory Journal, 55, 1901105. https://doi. org/10.1183/13993003.01105-2019

Lilley, E., Stanford, S. C., Kendall, D. E., Alexander, S. P., Cirino, G., Docherty, J. R., George, C. H., Insel, P. A., Izzo, A. A., Ji, Y., Panettieri, R. A., Sobey, C. G., Stefanska, B., Stephens, G., Teixeira, M., \& Ahluwalia, A. (2020). ARRIVE 2.0 and the British Journal of Pharmacology: Updated guidance for 2020. British Journal of Pharmacology, 177, 3611-3616. https://doi.org/10.1111/ bph.15178

Markovics, A., Szoke, É., Sándor, K., Börzsei, R., Bagoly, T., Kemény, Á., Elekes, K., Pintér, E., Szolcsányi, J., \& Helyes, Z. (2012). Comparison of the anti-inflammatory and anti-nociceptive effects of cortistatin-14 and somatostatin-14 in distinct in vitro and in vivo model systems. Journal of Molecular Neuroscience, 46, 40-50. https://doi.org/10.1007/ s12031-011-9577-4

Matthay, M. A., McAuley, D. F., \& Ware, L. B. (2017). Clinical trials in acute respiratory distress syndrome: Challenges and opportunities. The Lancet Respiratory Medicine, 5, 524-534. https://doi.org/10.1016/S22132600(17)30188-1 
Mehta, P., McAuley, D. F., Brown, M., Sanchez, E., Tattersall, R. S., Manson, J. J., \& HLH Across Speciality Collaboration, UK. (2020). COVID-19: Consider cytokine storm syndromes and immunosuppression. Lancet, 395, 1033-1034. https://doi.org/10.1016/S0140-6736 (20)30628-0

Morell, M., Camprubí-Robles, M., Culler, M. D., de Lecea, L., \& Delgado, M. (2014). Cortistatin attenuates inflammatory pain via spinal and peripheral actions. Neurobiology of Disease, 63, 141-154. https://doi.org/10. 1016/j.nbd.2013.11.022

Percie du Sert, N., Hurst, V., Ahluwalia, A., Alam, S., Avey, M. T., Baker, M., Browne, W. J., Clark, A., Cuthill, I. C., Dirnagl, U., Emerson, M., Garner, P., Holgate, S. T., Howells, D. W., Karp, N. A., Lazic, S. E., Lidster, K., MacCallum, C. J., Macleod, M., ... Würbel, H. (2020). The ARRIVE guidelines 2.0: Updated guidelines for reporting animal research. British Journal of Pharmacology, 177, 3617-3624. https://doi. org/10.1111/bph.15193

Prasse, A., Zissel, G., Lützen, N., Schupp, J., Schmiedlin, R., GonzalezRey, E., Rensing-Ehl, A., Bacher, G., Cavalli, V., Bevec, D., Delgado, M., \& Müller-Quernheim, J. (2010). Inhaled vasoactive intestinal peptide exerts immunoregulatory effects in sarcoidosis. American Journal of Respiratory and Critical Care Medicine, 182, 540-548. https://doi.org/ 10.1164/rccm.200909-14510C

Qiu, C., Li, J., Luo, D., Chen, X., Qu, R., Liu, T., Li, F., \& Liu, Y. (2020). Cortistatin protects against inflammatory airway diseases through curbing CCL2 and antagonizing NF- $\mathrm{kB}$ signaling pathway. Biochemical and Biophysical Research Communications, 531, 595-601. https://doi. org/10.1016/j.bbrc.2020.07.088

Reddy, G. K., \& Enwemeka, C. S. (1996). A simplified method for the analysis of hydroxyproline in biological tissues. Clinical Biochemistry, 29, 225-229. https://doi.org/10.1016/0009-9120(96)00003-6

Rol, A., Todorovski, T., Martin-Malpartida, P., Escola, A., González-Rey, E., Aragón, E., Verdaguer, X., Vallès-Miret, M., Farrera-Sinfreu, J., Puig, E., \& Fernández-Carneado, J. (2021). Structure-based design of a cortistatin analogue with immunoregulatory activity in models of inflammatory bowel disease. Nature Communications, 12, 1869. https://doi. org/10.1038/s41467-021-22076-5

Scavone, C., Brusco, S., Bertini, M., Sportiello, L., Rafaniello, C., Zoccoli, A., Berrino, L., Racagni, G., Rossi, F., \& Capuano, A. (2020). Current pharmacological treatments for COVID-19: What's next? British Journal of Pharmacology, 177, 4813-4824. https://doi.org/10.1111/bph.15072

Souza-Moreira, L., Morell, M., Delgado-Maroto, V., Pedreño, M., MartinezEscudero, L., Caro, M., O'Valle, F., Luque, R., Gallo, M., de Lecea, L., Castaño, J. P., \& Gonzalez-Rey, E. (2013). Paradoxical effect of cortistatin treatment and its deficiency on experimental autoimmune encephalomyelitis. Journal of Immunology, 191, 2144-2154. https:// doi.org/10.4049/jimmunol.1300384
Tager, A. M., LaCamera, P., Shea, B. S., Campanella, G. S., Selman, M., Zhao, Z., Polosukhin, V., Wain, J., Karimi-Shah, B. A., Kim, N. D., Hart, W. K., Pardo, A., Blackwell, T. S., Xu, Y., Chun, J., \& Luster, A. D. (2008). The lysophosphatidic acid receptor LPA1 links pulmonary fibrosis to lung injury by mediating fibroblast recruitment and vascular leak. Nature Medicine, 14, 45-54. https://doi.org/10. 1038/nm1685

Tsushima, K., King, L. S., Aggarwal, N. R., De Gorordo, A., D'Alessio, F. R., $\&$ Kubo, K. (2009). Acute lung injury review. Internal Medicine, 48, 621-630. https://doi.org/10.2169/internalmedicine.48.1741

Tug, T., Kara, H., Karaoglu, A., Karatas, F., Turgut, N. H., Ayan, E., Boran, C., \& Tug, E. (2013). The effect of octreotide, an analog of somatostatin, on bleomycin-induced interstitial pulmonary fibrosis in rats. Drug and Chemical Toxicology, 36, 181-186. https://doi.org/10.3109/ 01480545.2012 .710618

Wang, J., Wang, L., Song, G., \& Han, B. (2013). The mechanism through which octreotide inhibits hepatic stellate cell activity. Molecular Medicine Reports, 7, 1559-1564. https://doi.org/10.3892/mmr.2013.1385

Wynn, T. A. (2011). Integrating mechanisms of pulmonary fibrosis. The Journal of Experimental Medicine, 208, 1339-1350. https://doi.org/10. 1084/jem.20110551

Wynn, T. A., \& Ramalingam, T. R. (2013). Mechanisms of fibrosis: Therapeutic translation for fibrotic disease. Nature Medicine, 18, 10281040.

Zhou, F., Yu, T., Du, R., Fan, G., Liu, Y., Liu, Z., Xiang, J., Wang, Y., Song, B., $\mathrm{Gu}, \mathrm{X}$., \& Guan, L. (2020). Clinical course and risk factors for mortality of adult inpatients with COVID-19 in Wuhan, China: A retrospective cohort study. Lancet, 395, 1054-1062. https://doi.org/10.1016/ S0140-6736(20)30566-3

\section{SUPPORTING INFORMATION}

Additional supporting information may be found online in the Supporting Information section at the end of this article.

How to cite this article: Barriga, M., Benitez, R., Ferraz-dePaula, V., Garcia-Frutos, M., Caro, M., Robledo, G., O'Valle, F., Campos-Salinas, J., \& Delgado, M. (2021). Protective role of cortistatin in pulmonary inflammation and fibrosis. British Journal of Pharmacology, 1-21. https://doi.org/10.1111/bph. $\underline{15615}$ 